\title{
Intrastriatal Grafts Derived from Fetal Striatal Primordia. I. Phenotypy and Modular Organization
}

\author{
Ann M. Graybiel, ${ }^{1}$ Fu-Chin Liu, ${ }^{1}$ and Stephen B. Dunnett ${ }^{2}$ \\ 'Department of Brain and Cognitive Sciences, Massachusetts Institute of Technology, Cambridge, Massachusetts 02139, \\ and ${ }^{2}$ Department of Experimental Psychology, University of Cambridge, Cambridge CB2 3EB, England
}

Fetal striatal grafts display a striking modularity of composition. With acetylcholinesterase (AChE) histochemistry, the tissue of such grafts can be divided into regions with strong AChE staining of the neuropil and regions in which AChE staining of the neuropil is weak. In the experiments reported here, we reexamined the nature of this modularity. Striatal grafts were made by injecting dissociated cells of E15 ganglionic eminence into the striatum of adult rats, which 7 days before had recived intrastriatal deposits of ibotenic acid. Some donors had been exposed to ${ }^{3} \mathrm{H}$-thymidine at E11E15. After 9-17 month survivals, the anatomical organization of the grafts was studied by histochemistry, immunohistochemistry, and autoradiography.

In every graft, the AChE-rich regions formed patches (P regions) in a larger $A C h E-p o o r$ surround (NP regions). Neurons labeled with ${ }^{3} \mathrm{H}$-thymidine appeared in both $\mathrm{P}$ and NP regions, suggesting that donor cells were distributed in each type of region and that neither type of tissue, $P$ or NP, was composed exclusively of host tissue. In the AChE-rich P regions, markers characteristic of normal perinatal and mature rat striatum were expressed by medium-sized cells: calcium-binding protein (calbindin $D_{28 \mathrm{~K}}$ ) immunostaining, metenkephalin (mENK) immunostaining, and, more rarely, somatostatin (SOM) immunostaining. In the NP regions, however, medium-sized cells expressing calbindin and mENK immunostaining were very rare, and there was an abundance of neuronal types not found in normal mature striatal tissue. These included (1) large, multipolar, calbindin-positive neurons with well-ramified, densely stained dendrites, (2) large, SOM-positive neurons with prominent dendritic trees, and (3) mENK-positive cells smaller than typical striatal, mediumsized, mENK-immunoreactive neurons. In NissI stains, the AChE-rich P regions resembled the normal striatum of mature animals, whereas the AChE-poor NP regions did not.

These findings suggest that the $P$ regions of fetal striatal grafts achieve a phenotypy similar to that of normal striatum

\footnotetext{
Received Nov. 15, 1988; revised Feb. 27, 1989; accepted Mar. 15, 1989.

This work was funded by NATO grant RG.85/0180 for International Collaboration in Research, by NSF BNS83-19547 and BNS-8720475, and by the Seaver Institute. We thank Drs. J. H. Fallon, R. P. Elde, C. R. Gerfen, and P. C. Emson for gifts of antisera; Drs. S. Jhaveri, A. D. Lander, B. Quinn, and O. Isacson for their comments on the manuscript; Mr. G. Holm for help with the immunohistochemistry; and Mr. H. F. Hall, who is responsible for the photography.

Correspondence should be addressed to Ann M. Graybiel, Ph.D., Department of Brain and Cognitive Sciences, Massachusetts Institute of Technology, E25-618, 45 Carleton Street, Cambridge, MA 02139.

Copyright (C) 1989 Society for Neuroscience 0270-6474/89/093250-22\$02.00/0
}

at maturity and during much of postnatal development. The dominant expression of perikaryal calbindin-like immunoreactivity in the $P$ regions further suggests that these zones have a high proportion of tissue resembling striatal matrix. By contrast, expression of marker antigens in the NP zones of the grafts suggests that these zones are predominantly composed of nonstriatal tissue or that they have the phenotypy of immature striatum intermixed with some nonstriatal cells. We conclude that although some striosome-matrix compartmentalization may be reconstituted within $\mathbf{P}$ zones, the modular organization of fetal striatal grafts may principally reflect an atypical compartmentalization of different tissue types.

Fetal striatal grafts provide a potentially powerful experimental system for studying the determinants of neutotransmitter-specific neural development. Several research groups have demonstrated that cells derived from the embryonic ganglionic eminence survive transplantation to the striatum of the adult rat and express a variety of neurotransmitter- and receptor-related markers characteristic of normal striatal tissue (Isacson et al., 1984, 1985, 1987; Pritzel et al., 1986; Walker et al., 1987; Deckel and Robinson, 1987; Sanberg et al., 1987; Graybiel et al., 1987a; Clarke et al., 1988; Roberts and DiFiglia, 1988). In the most systematic study so far, Isacson et al. (1987) have shown that such grafts develop a compartmentalized organization in which markers for neutotransmitter-related compounds are arranged in macroscopic patches visible in sections through the grafts. These authors found that acetylcholinesterase (AChE) staining, a variety of neuropeptide-immunoreactive neurons, fibers immunoreactive for tyrosine hydroxylase (TH) and for met-enkephalin-like peptide (mENK), and ligand binding for dopamine D2, muscarinic cholinergic, and opiate receptors all showed a patchy distribution within the grafts. Most remarkably, a substantial overlap was observed among the patches detected by the different markers.

Compartmentalization of transmitter-related markers is now well characterized in the normal striatum (see, e.g., Graybiel and Ragsdale, 1983; Gerfen, 1984; Gerfen et al., 1985, 1987a, b; Graybicl, 1986, 1989). In particular, the correspondence of zones detectable in $\mathrm{AChE}$ stains with patches observed with markers for $\mathrm{mENK}$ and substance $\mathrm{P}$ (SP)-like peptides, $\mathrm{TH}$, and various receptor-related ligands is a landmark feature of the striosomal system of the striatum. In the immature striatum, future striosomes express high AChE activity and TH-like immunoreactivity (Butcher and Hodge, 1976; Graybiel et al., 1981). By contrast, the striosomes at maturity show relatively weaker AChE staining and TH-like immunoreactivity than the matrix 
in which they lie embedded (Graybiel and Ragsdale, 1978; Graybiel et al., 1987b; Ferrante and Kowall, 1987).

As pointed out by Isacson et al. (1987), the staining characteristics of fetal striatal grafts more closely resemble those of immature striatum than those of mature striatum: they have AChE-rich, TH-rich patches in a weakly staining or unstained surround. This led Isacson et al. (1987) to suggest that the tissue of the grafts, lacking normal environmental cues, might have established compartmental order but maintained the immature form of this compartmentalization. The possibility that striatal grafts exhibit such an arrested development would have important implications for understanding what molecular cues are involved in the initiation and subsequent maturation of compartmentalization in the striatum. Immature characteristics of the grafts would also raise new questions about how the grafts exert their functional influence on host behavior (Björklund et al., 1987). There is, however, a major problem in evaluating the developmental status of the graft tissue. Many of the transmitter-related markers that were first employed to identify mature and immature striosomes in the cat and primate do not identify these compartments unambiguously in the striatum of the rat. In this species, mature striosomes cannot always be clearly identified either by heterogeneity of $\mathrm{AChE}$ activity (as was originally employed to define striosomes in other species) or on the basis of other markers, such as low TH-like immunoreactivity in the striosomal neuropil (see Butcher, 1983; Hökfelt et al., 1984; Fallon and Loughlin, 1987). Indeed, individual markers are not always secure identifiers of striosomes even in primates and cats because of regional differences in their expression in different parts of the striatum (Graybiel and Ragsdale, 1983; Besson et al., 1988b). Accordingly, in the striatal grafts, the patches rich in AChE activity and in TH-like, mENK-like, and SP-like immunostaining, surrounded by another compartment poor in all these markers, need not necessarily be immature striosomes embedded in immature matrix tissue.

In the experiments reported here, we set out to reexamine the compartmental organization of fetal striatal grafts in an effort to determine (1) whether both the AChE-rich regions and the AChE-poor regions of the grafts are composed of donor tissue, (2) whether both the AChE-rich and the AChE-poor regions are striatal tissue, and (3) whether the AChE-rich regions, if striatal, more closely resemble striosomes, matrix, or both.

\section{Materials and Methods}

Host animals. Surgeries were performed on 20 adult Sprague-Dawley rats (Charles River Laboratories, Inc.) deeply anesthetized with Nembutal or Chloropent and mounted in a Kopf stereotaxic apparatus. In all of the rats, lcsions were made in the right caudoputamen by stereotaxic injection of the neurotoxin, ibotenic acid. Each rat received 6 deposits of $0.2 \mu \mathrm{l}$ of $10 \mu \mathrm{g} / \mu \mathrm{l}$ ibotenic acid (Sigma) in $0.1 \mathrm{M}$ phosphate

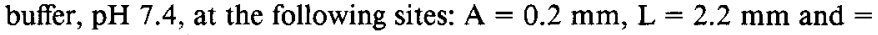
$3.7 \mathrm{~mm}$, and $A=1.7 \mathrm{~mm}, \mathrm{~L}=2.5 \mathrm{~mm}, \mathrm{~V}=4.0 \mathrm{~mm}$ and $5.5 \mathrm{~mm}$, with $\mathrm{A}$ measured from bregma, $\mathrm{L}$ from the midline, and $\mathrm{V}$ from the dura mater, the nose bar being set $-2.3 \mathrm{~mm}$ below the interaural line. Each aliquot was delivered over 2-3 min from a $10 \mu 1$ Hamilton syringe connected to a Harvard microdrive pump. One of these animals served as a control for the effects of ibotenic acid in the caudoputamen. The remaining 19 served as hosts for fetal striatal grafts.

Transplantation. Donor tissues were obtained from striatal primordia dissected from fetuses at embryonic day (E) 15 (crown-rump length 12$15 \mathrm{~mm}$ ). Donor fetuses had been exposed to ${ }^{3} \mathrm{H}$-thymidine at one embryonic day (E11, E12, E13, E14, or E15) by intraperitoneal injection of $1 \mathrm{mCi}{ }^{3} \mathrm{H}$-thymidine $(78.8 \mathrm{Ci} / \mathrm{mmol}$, New England Nuclear) into the pregnant mothers. The dissected fetal tissue was stored briefly in a solution containing $0.6 \%$ glucose and $0.9 \%$ saline at room temperature, then incubated for $20 \mathrm{~min}$ at $37^{\circ} \mathrm{C}$ in $0.1 \%$ trypsin (Sigma, crude type
II) dissolved in the glucose-saline medium, rinsed 4 times with fresh glucose-saline solution, and mechanically dissociated by repeated gentle pipetting with a fire-polished Pasteur pipette. Aliquots of the resulting stock suspension were loaded into the injection syringe just before the injection protocol began. Several rats received injections of the same stock suspension. The final suspensions contained cells from approximately 3 dissected specimens per $10 \mu \mathrm{l}$ of medium. Seven to $8 \mathrm{~d}$ after the ibotenic acid injections, 9 rats received unilateral right-side ( 1 died after the surgery) and 10 rats bilateral striatal cell suspension grafts at the following coordinates: $\mathrm{A}=0.9 \mathrm{~mm}, \mathrm{~L}= \pm 3.0 \mathrm{~mm}$, and $\mathrm{V}=4.7$ $\mathrm{mm}$. The hemispheres without lesions also received unilateral grafts at the same coordinates; these will be described in a separate report. Three microliters of the cell suspension were injected at each site over a 3-5min (or, in 1 rat, 30-min) period. After the injection, a 5-min period was allowed for diffusion before slow retraction of the needle. Calculations based on those by Isacson (1987) suggest that this procedure yields a total of approximately $405 \times 10^{3}$ donor cells injected per hemisphere (estimated $150 \times 10^{3}$ cells $/ \mu 1$ cell suspension, $\times 90 \%$ in vitro survival rate, $\times 3 \mu$ l injected).

Tissue processing. Nine to 17 months after grafting, the host animals were deeply anesthetized and all but one were perfused transcardially with $500 \mathrm{ml}$ of $4 \%$ paraformaldehyde in $0.1 \mathrm{M}$ phosphate buffer containing $5 \%$ sucrose and $0.9 \%$ saline (pH 7.4). Brains were postfixed at $4^{\circ} \mathrm{C}$ for $2-4 \mathrm{hr}$ in the same fixative and then immersed overnight in a solution of $20 \%$ sucrose and $0.9 \%$ saline made up in $0.1 \mathrm{M}$ phosphate buffer. In the single exceptional case, the brain was removed from the deeply anesthetized host and rapidly frozen in pulverized dry ice in preparation for ligand binding (see below). All perfused brains were cut in the coronal plane at $30 \mu \mathrm{m}$ on a freezing microtome. Sections were prepared for histochemistry, immunohistochemistry, or ligand binding in serial sequences, permitting comparisons among adjacent sections processed for different markers. All sections through the grafts were processed.

Immunohistochemistry and AChE histochemistry. For mENK, calcium-binding protein (calbindin- $\mathrm{D}_{28 \mathrm{~K}}$; Baimbridge et al., 1982), somatostatin (SOM), glial fibrillary acidic protein (GFAP), epidermal growth factor (EGF), and laminin immunohistochemistry, sections pretreated with methanolic $\mathrm{H}_{2} \mathrm{O}_{2}$, Triton $\mathrm{X}-100$, and normal goat serum were processed by the peroxidase-antiperoxidase method as described elsewhere (Graybiel, 1984a; Graybiel and Chesselet, 1984a). Dilutions of the antisera were: 1:1000 for mENK and 1:600 for SOM (1-28) antisera (both kindly provided by Dr. R. P. Elde), 1:500-1:1000 for calbindin antiscra (kindly donated by Dr. C. R. Gerfen and Dr. P. C. Emson), 1:500 for GFAP (Boehringer Mannheim, Federal Republic of Germany), 1:1000 for laminin (Gibco Laboratories), and 1:800 for EGF (kindly donated by Dr. J. H. Fallon). The primary incubation times for all antisera were $2-3 \mathrm{~d}$ at $4^{\circ} \mathrm{C}$. For EGF immunohistochemistry, some sections were processed in the laboratory of Dr. Fallon (Fallon et al., 1984). References to immunostaining (e.g., "mENK-like") refer only to immunoreactivity detected with the particular antisera specified.

AChE histochemistry was carried out according to a slightly modified Geneser-Jensen and Blackstad method (Geneser-Jensen and Blackstad, 1971), in which the sections were developed in potassium ferricyanide (Graybiel and Ragsdale, 1978). In some cases, selected sections were stained with cresylecht violet.

Receptor autoradiography. Sections from 4 perfused brains and 1 unperfused brain were incubated in $2.5 \mathrm{nM}{ }^{3} \mathrm{H}$-naloxone (New England Nuclear) and processed for opiate receptor binding by film-autoradiography as described by Herkenham and Pert (1982), with slight modifications (Besson et al., 1988a). Autoradiographic exposures (Amersham Hyperfilm) were for 10-12 weeks. Following autoradiography, sections were stained for AChE.

Thymidine autoradiography. Sections were mounted, defatted, dipped in Kodak NTB-2 emulsion [diluted 1:1 in distilled water containing $0.1 \%$ detergent (Dreft)], and developed as described elsewhere (Graybiel, 1984a) in Kodak D-19 after exposure times of 2-4 months. All autoradiographic sections were stained with cresylecht violet.

Analysis. Sections were examined with light- and dark-field optics, and elements of interest in individual sections were charted with a computerized plotting system or with the aid of a macroprojector. Charts of scrially adjoining sections werc aligned by reference to vascular landmarks. For charting of ${ }^{3} \mathrm{H}$-thymidine-labeled neurons, ca. 20 grains/ nucleus was taken as the threshold for considering the cell labeled. For estimates of cell diameters, the longest axis of the cell was taken; when possible, measurements were made through the plane of the nucleus. 

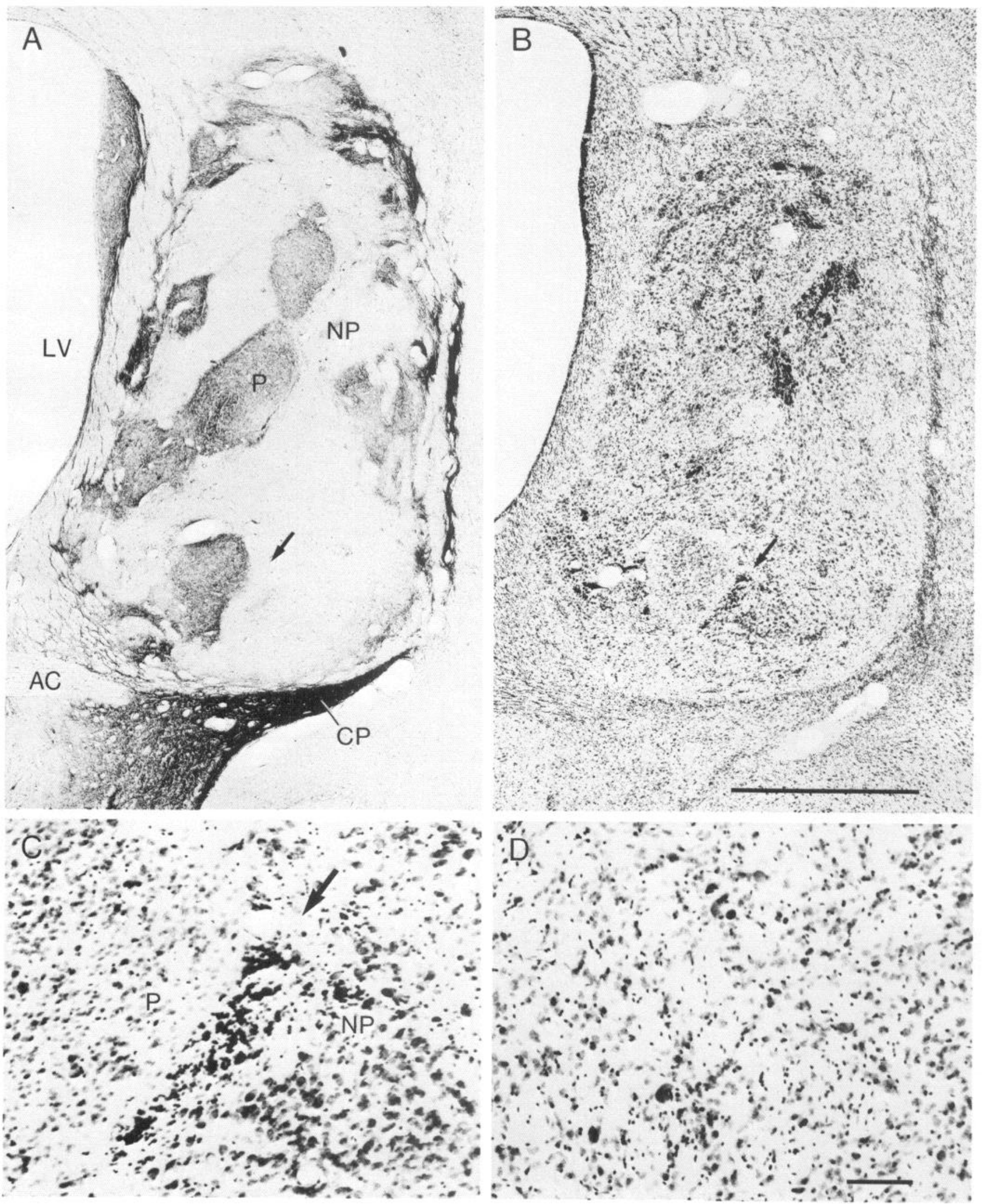

Figure 1. $A$ and $B$, Serially adjoining sections through a fetal striatal graft illustrating, in $A$, AChE-rich $\mathrm{P}$ and AChE-poor NP compartments in the graft visible with acetylthiocholinesterase histochemistry and, in $B$, the heterogeneous cellular architecture of the grafts visible with Nissl stains. Scale bar for $A$ and $B$, shown in $B$, indicates $1 \mathrm{~mm}$. Case RSG2-21, postgraft survival time 13 months. AChE-poor fiber bundles form a ring around the graft separating it from the thin rim of host striatal tissue $(C P)$ that survived the ibotenic acid lesion placed there 7 days before injection of the fetal cell suspension. Arrows in $A$ and $B$ point to the thin zone of small, intensely stained cells (presumably glia) separating an AChE-rich P region 


\section{Results}

\section{AChE histochemistry and Nissl staining}

The control brain containing an ibotenic acid lesion without graft confirmed that massive striatal damage was inflicted by the ibotenic acid injections (Coyle and Schwarcz, 1976; Köhler and Schwarcz, 1983; Isacson et al., 1987; Walker et al., 1987). In each brain containing a graft, the tissue of the transplant formed a distinctly delimited zone lying within the part of the host striatum that remained in the wake of the ibotenic acidinduced lesion. AChE staining in all of the grafts had the typically patchy appearance already reported by Isacson et al. (1985, 1987) and Walker et al. (1987). An example is shown in Figure $1 A$. Within the graft, zones of high AChE activity [here called "patch" (P) regions] lay embedded in surrounding tissue [here called "nonpatch" (NP) regions], in which the AChE activity was much weaker. The sizes of the grafts and the proportion of the grafts taken up by the intensely AChE-positive patches differed from brain to brain. These variations and other characteristics of the AChE staining will be discussed in a separate report.

Sections stained for Nissl substance (Fig. $1 B$ ) showed that the transplanted tissue was composed of neurons and small intensely stained cells (presumably glia). Cellular clusters of varying size appeared within each graft. When adjoining Nissl-stained and AChE-stained sections were compared, it became apparent that some of the cellular clusters were in register with AChErich $\mathrm{P}$ regions, whereas others were not (Fig. 1, $A, B$ ). Typical examples of each type are shown at high magnification in Figure $1 C$. The AChE-rich $P$ region corresponds to a zone containing predominantly medium-sized neurons (ca. 10-16 $\mu \mathrm{m}$ diameter), a few large neurons (ca. $25 \mu \mathrm{m}$ diameter), and some small glial cells. The sizes and relative proportions of medium and large diameter cells in this cluster are similar to those of the normal host striatum (Fig. 1D). This $\mathrm{P}$ cell cluster was particularly clearly delimited from the remainder of the graft tissue by a cellpoor margin.

In contrast to the AChE-rich $\mathrm{P}$ regions, the AChE-poor NP regions had a highly heterogeneous cellular composition that did not resemble striatal tissue of the normal adult rat (Fig. 1, $\left.B, C^{\prime}\right)$. The aggregate of NP cells shown at high magnification in Figure $1 C$ contains a mixed population of neurons ca. 13$31 \mu \mathrm{m}$ in diameter, many of them larger than striatal medium spiny cells (average diameter ca. $14 \mu \mathrm{m}$, see Fig. $1 D$ ). As sometimes occurred elsewhere, this NP zone was separated from the adjoining $P$ region by a thin wall of small (presumably glial) cells. Otherwise, it blended into adjoining parts of the NP zone without abrupt borders. Elsewhere in the NP tissue, there were zones containing even larger neurons and other zones containing smaller neurons.

\section{Laminin immunostaining}

To assess the vascular structure of the graft, we employed an antiserum against laminin, a glycoprotein in the basement membranes of blood vessels (Eriksdotter-Nillson et al., 1986). Interestingly, prominent laminin-positive blood vessels were found

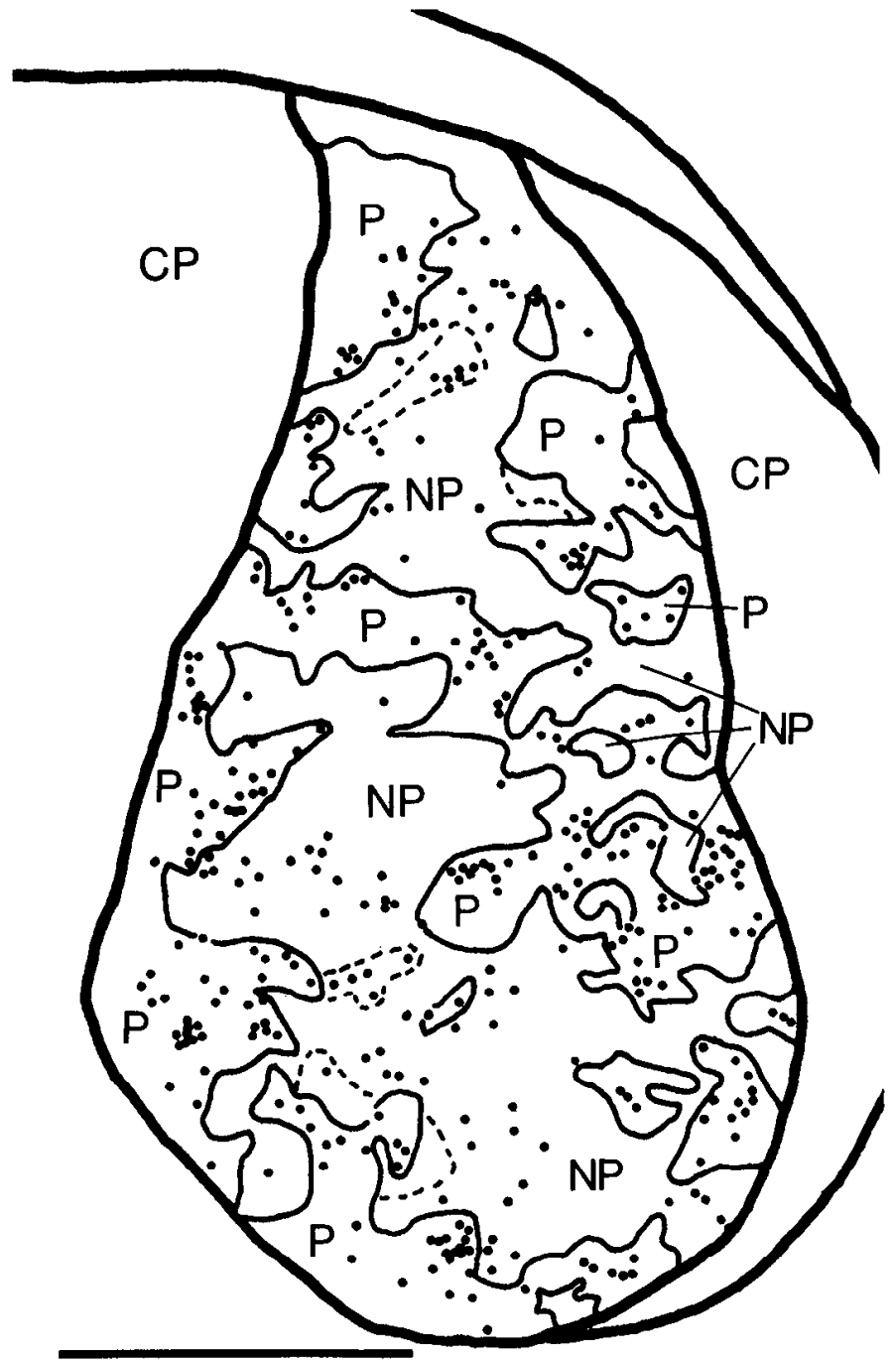

Figure 2. Chart illustrating the distribution of ${ }^{3} \mathrm{H}$-thymidine-labeled neurons (black dots) present in a section processed for autoradiography. Case RSG2-33, postgraft survival time 9 months. The donor tissue was exposed to ${ }^{3} \mathrm{H}$-thymidine at E15. Solid outlines indicate borders of the AChE-rich $\mathrm{P}$ regions visible in a serially adjoining section stained for AChE. Dotted lines indicate borders of weakly stained zones. Note that ${ }^{3} \mathrm{H}$-thymidine-labeled neurons are present both in $\mathrm{P}$ and in NP regions of the graft, but they do not appear in the surrounding striatal tissue of the host $(C P)$. Scale bar, $1 \mathrm{~mm}$.

in rings encircling some of the grafts. Laminin-positive vessels of varying diameters appeared within the transplant. However, neither neurons nor neuropil in the $P$ and the NP regions contained detectable laminin-like immunoreactivity.

Donor origin of labeled neurons in patch and nonpatch regions ${ }^{3} \mathrm{H}$-thymidine neuronography was used to test whether the modular expression of striatal markers was the result of a strict separation of labeled graft and unlabeled host tissue. We exposed donor animals to ${ }^{3} \mathrm{H}$-thymidine at times (E11-E15) known to

from neighboring AChE-poor NP tissue. This region is shown at higher magnification in $C$, with the arrow as fiducial marker pointing to same site as arrows in $A$ and $B . D$, Normal striatal tissue of the contralateral host's striatum. Scale bar for $C$ and $D$, shown in $D$, indicates $100 \mu$ m. Comparison of $C$ and $D$ shows that neuronal phenotypes in $\mathbf{P}$ regions resemble those of the host's striatum, whereas those in NP regions do not. $L V$, lateral ventricle; $A C$, anterior commissure. 

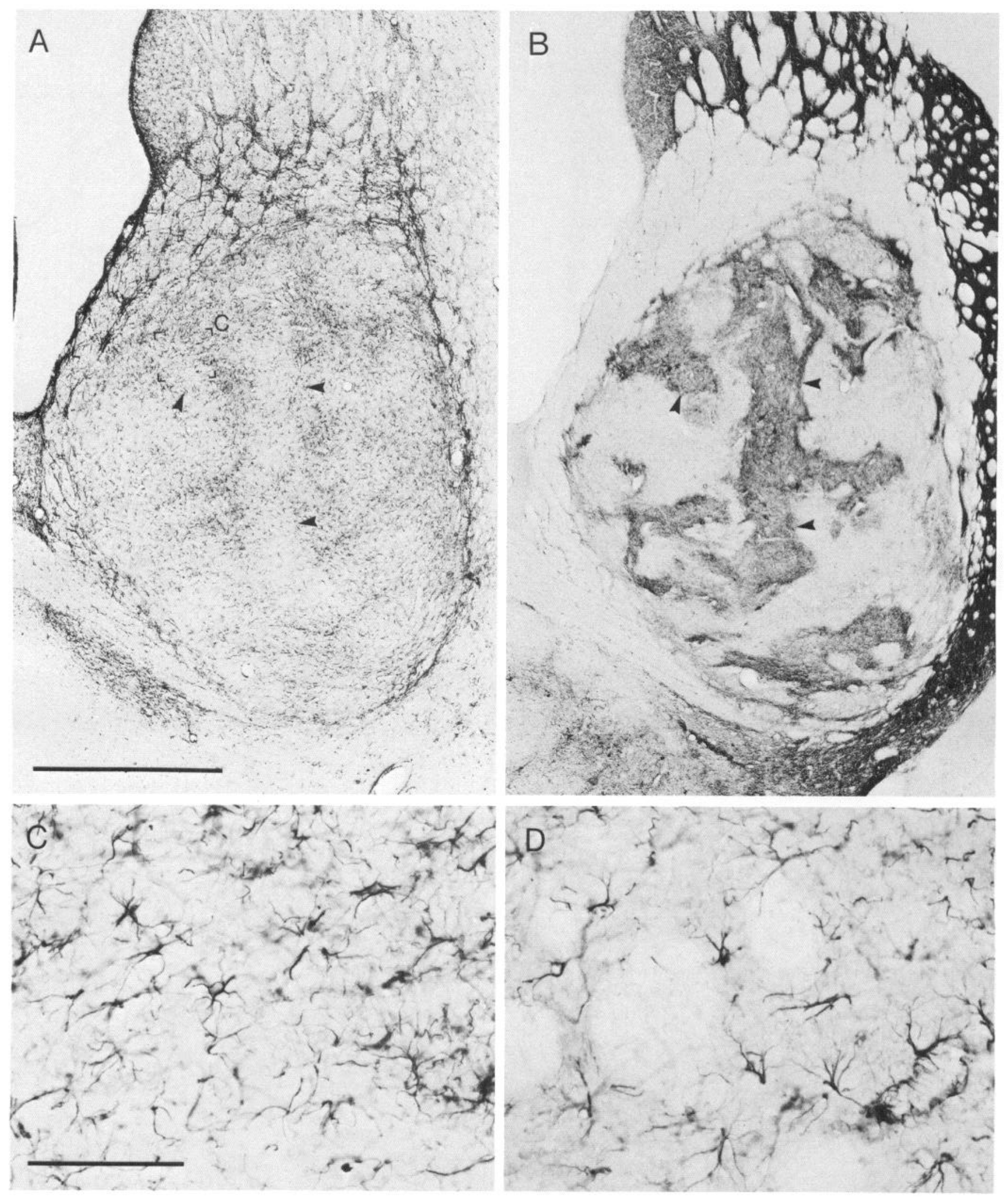

Figure 3. $A$ and $B$, Serially adjoining sections through fetal striatal graft stained for GFAP-like immunoreactivity $(A)$ and for AChE activity $(B)$. From RSG2-32, postgraft survival time 12 months. The 3 arrowheads in $A$ and in $B$ mark corresponding locations. Note that many GFAPimmunoreactive cells border AChE-rich P regions, but that these cells also occur elsewhere in NP tissue and within P regions. Scale bar for $A$ and $B$, shown in $A$, indicates $1 \mathrm{~mm}$. Zone marked by brackets in $A$ and labeled $C$ is illustrated at higher magnification in panel $C$. Compare with field of GFAP-positive cells in normal striatum on the contralateral side of the host's brain $(D)$. Scale bar for $C$ and $D$, shown in $C$, indicates $100 \mu$ m. 


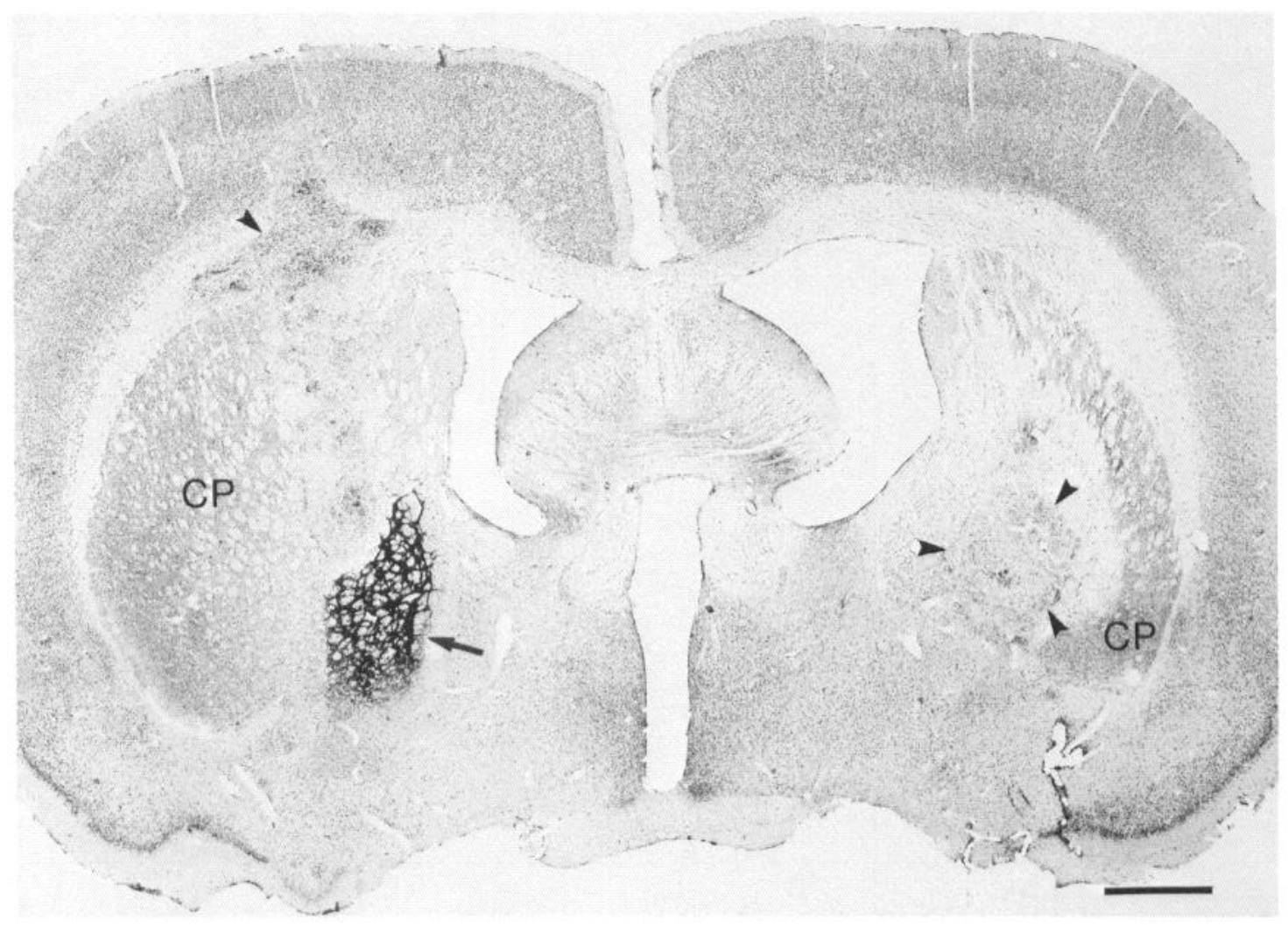

Figure 4. Cross section through host brain stained for EGF-like immunoreactivity. From case RSG2-24, postgraft survival 17 months. On right, borders of the graft are indicated by arrowheads. A rim of striatal tissue of the host $(C P)$ remains, separated from the graft by fiber bundles. Single arrowhead on left indicates dorsal part of graft introduced into this side (without a prior injection of ibotenic acid). At arrow on left, dense EGFlike immunoreactivity marks the globus pallidus. On the right, the ibotenic acid injection apparently resulted in loss of pallidal neuropil of the host at the transverse level illustrated, but farther caudally, EGF-positive pallidal neuropil was present on this side. Note that the grafts do not express EGF-like immunoreactivity. Scale bar, $1 \mathrm{~mm}$.

coincide with the first half of neurogenesis in the rat's striatum and, in the resulting grafts, plotted the distribution of labeled neurons relative to the $\mathrm{AChE}$-positive $\mathrm{P}$ regions.

Labeled neurons were strictly confined to the graft tissue and did not appear in the host striatum. Few neurons were labeled with E11 and E12 exposures. Many more labeled neurons were present in the transplants from donor animals exposed at E13E15. The disposition of ${ }^{3} \mathrm{H}$-thymidine labeled neurons in a graft derived from E15 donor tissue is shown in Figure 2. Labeled neurons appeared both in the $\mathrm{P}$ and in the NP regions in this graft and in all others studied.

\section{Glial and pallidal markers in the graft tissue}

Given that the NP regions of the grafts did not express the typically high levels of $\mathrm{AChE}$ characteristic of mature striatal tissue, it was important to check whether these AChE-poor NP zones contained high proportions of nonstriatal or even nonneural tissue. We began by staining sections from 3 cases for GFAP-like immunoreactivity to identify the distribution of astrocytes (Bignami et al., 1972). As shown in Figure $3 A$, in addition to the many GFAP-positive cells at the borders of the implants, GFAP-immunoreactive cells were distributed throughout the grafts. The immunoreactive cells had the typically multipolar appearance of astrocytes and appeared similar to the GFAP-positive cells of the host striatum (Fig. 3, $C, D$ ). Particularly high densities of GFAP-immunoreactive cells sometimes occurred at the borders between AChE-rich $\mathrm{P}$ and AChE-poor NP regions, but many also appeared within subfields of the $\mathrm{P}$ and NP regions (Fig. 3, $A, B$ ). No singular relationship was found between the distribution of GFAP-positive cells and the locations of NP or P regions within the grafts.

We next tested the possibility that the grafts might contain pallidal tissue derived from pallidal progenitor cells included in the dissection of striatal primordia (Walker et al., 1987; DiFiglia et al., 1988). Sections from 4 cases were immunostained with an antiserum to EGF that binds to fibers in mature pallidal tissue and tissue of the pallidal "type" located in the mature substantia nigra and olfactory tubercle but does not bind in the striatum (Fallon et al., 1984). EGF-like immunoreactivity was not detectable either in the AChE-rich P regions or in the AChEpoor NP regions of the grafts despite being present in the host pallidum in the same brains (Fig. 4). We also stained for calbindin-like immunoreactivity to test whether the grafts contained large calbindin-positive neurons that resembled calbindin-positive neurons found in the caudal part of the host pallidum. As described in the next section, many such neurons were found in the grafts.

\section{Striatal markers expressed in the graft tissue}

Taken together, the results of the Nissl, GFAP, and EGF staining showed that the $\mathrm{P}$ regions of the grafts are not islands of nerve cells embedded in an NP surround made up of noncellular or 

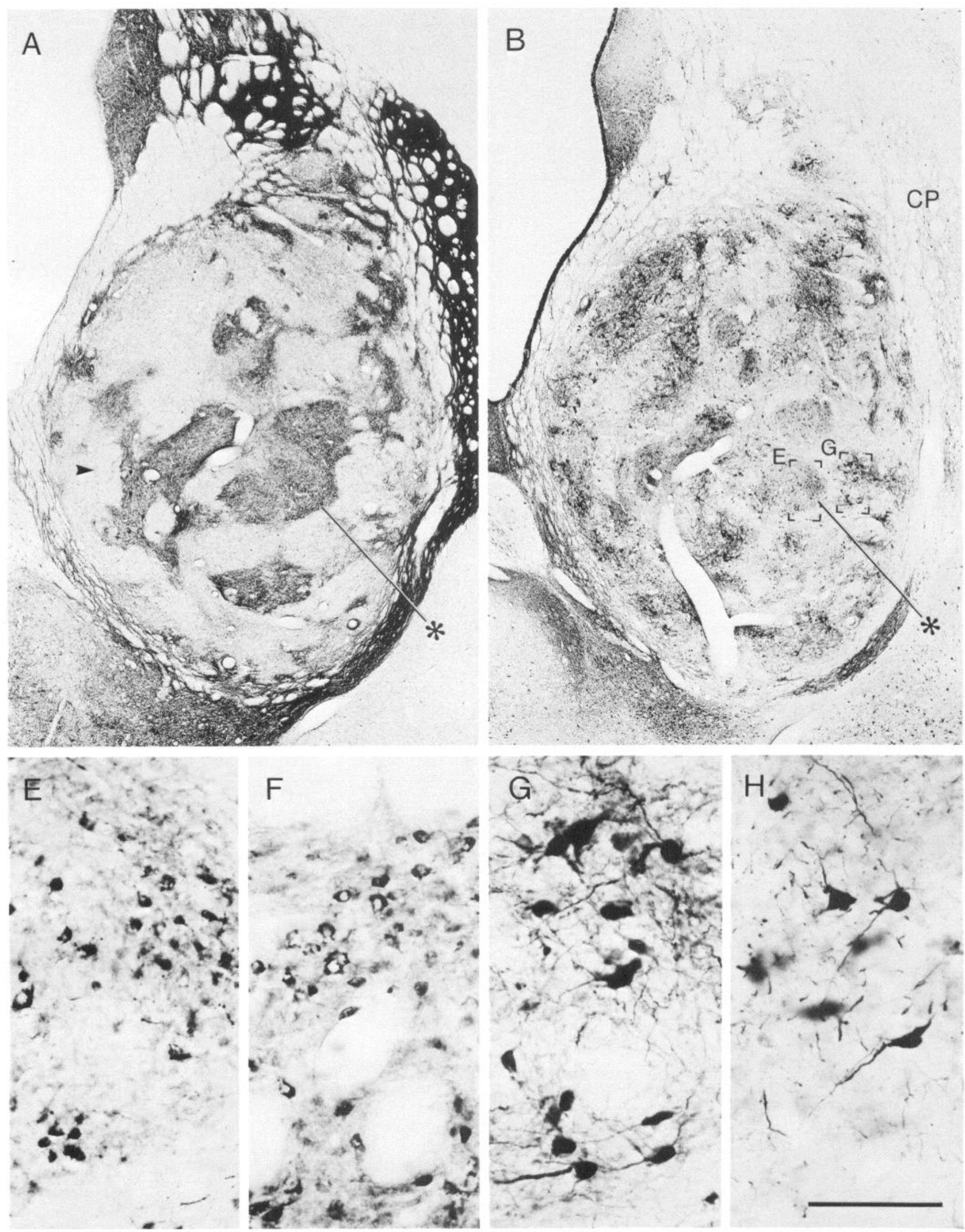

Figure 5. $A, B$, and $C$, Serially adjacent sections stained for AChE activity $(A)$, calbindin-like immunoreactivity $(B)$, and mENK-like immunoreactivity $(C)$ to illustrate large graft in case RSG2-32, postgraft survival 12 months. Asterisks indicate one of the AChE-rich P regions in the graft. $D$, Overlay drawing of patterns in sections shown in $A$ and $C$, illustrating schematically the overlap of the AChE-rich P regions in $A$ (pale stipple) and the clusters of calbindin-positive medium-sized neurons visible in $B$ (dark stipple). Note that nearly every cluster of calbindin-positive mediumsized neurons is within an AChE-rich P region. Dashed lines indicate zones of weak AChE staining; fine lines indicate borders of blood vessels. Scale bar for $A-D$, shown in $C$ indicates $1 \mathrm{~mm}$. $E-L$, Photomicrographs illustrating calbindin-positive cells $(E-J)$ and mENK-positive cells $(K, L)$. Scale bar for $E-L$, shown in $H$, indicates $100 \mu \mathrm{m}$. $E, G$, and $K$, Fields indicated by brackets with corresponding letters in low-power photographs 

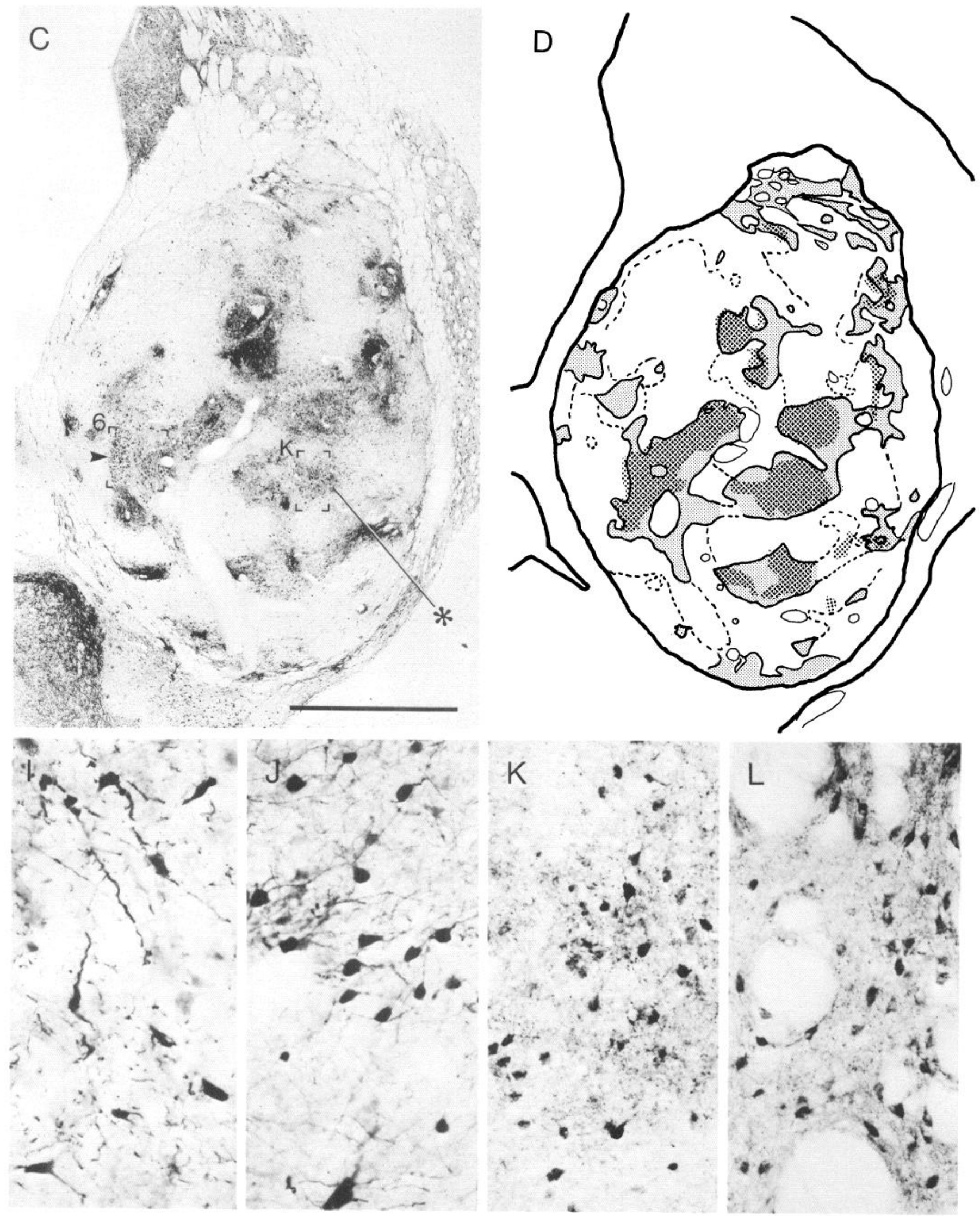

of $B$ and $C$. Bracketed field in $C$ marked 6 is shown at higher magnification in Figure 6. Arrowhead in $A$ points to edge of mENK-positive zone shown in the bracketed region (at arrowhead) in $C$. E. Clustered calbindin-immunoreactive medium-sized neurons in $\mathrm{P}$ region. Compare with similar neurons of the host's striatum, shown in $F$. $G$, Medium- and large-sized multipolar calbindin-positive neurons with well-stained dendrites found in NP region of the graft. Compare with the similar calbindin-positive neurons found in the host's basolateral amygdala $(H)$ and caudal pallidum $(I)$ and with neurons with similar morphology but smaller size found in the ventrolateral cortex of the host $(J)$. $K$, mENK-immunoreactive medium-sized neurons in an AChE-rich P region. These mENK-positive neurons resemble those of the host striatum (examples shown in $L$ ). 


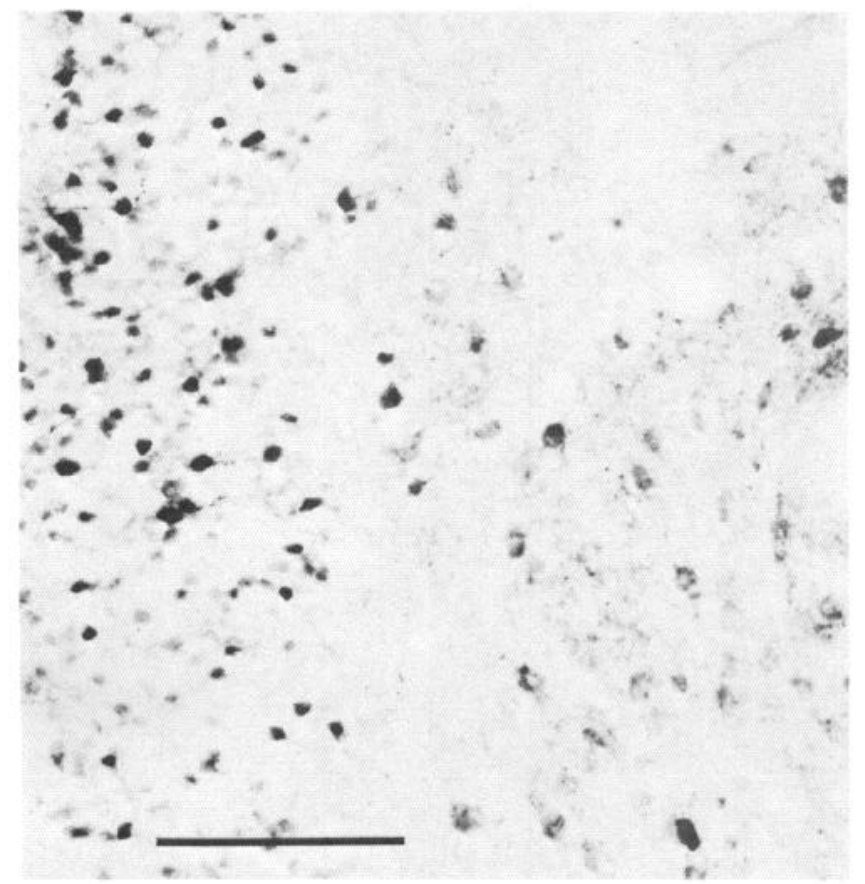

Figure 6. Enlargement of bracketed region marked 6 in Figure $5 C$, shown to illustrate small mENK-positive neurons in an NP zone (left side of field). Some typical medium-sized mENK-positive neurons appear in the right side of the field, which lies in an AChE-rich $\mathrm{P}$ region. Scale bar, $100 \mu \mathrm{m}$.

glial tissue. The next issue we addressed was whether both $\mathrm{P}$ and NP regions contained striatal tissue. There is no known molecular marker specific for all striatal neurons and only striatal neurons. Immunostaining for a $28 \mathrm{KDa}$ calcium-binding protein (calbindin), however, is characteristic of medium-sized neurons of the extrastriosomal matrix in a large part of the mature striatum (Gerfen et al., 1985) and also in a large part of the immature striatum (F.-C. Liu et al., unpublished observations). mENK-like immunoreactivity is also characteristic of a large proportion of striatal neurons (Graybiel and Chesselet, 1984a, b; Besson et al., 1986, 1988b). We employed each of these markers.

\section{Immunostaining for calbindin-like immunoreactivity}

Immunostaining for calbindin was carried out in 14 rats. The 2 calbindin antisera employed yielded similar patterns of immunostaining. In the host striatum, the calbindin antibodies stained medium-sized neurons and neuropil except in the dorsolateral and lateral parts of the caudoputamen and in small gaps shown by Gerfen et al. (1985) to correspond to ${ }^{3} \mathrm{H}$-naloxone-positive patches (striosomes). In the graft tissue, calbindinlike staining was highly heterogeneous (Fig. $5 B$ ) and appeared in regions corresponding to both $\mathrm{P}$ and $\mathrm{NP}$ zones identified in adjacent sections stained for AChE (Fig. 5A).

The character of the elements stained in the P and NP compartments differed sharply from one another. In the AChE-rich $P$ regions, nearly all of the calbindin-positive neurons were medium-sized (ca. 10-16 $\mu \mathrm{m}$ diameter) and appeared similar to those in the host striatum (Fig. 5, E, F). The cell bodies were stained, but dendrites were rarely visible. When dendritic segments were detected, they were short and thin. These mediumsized calbindin-positive neurons and the associated neuropil tended to form distinct aggregates within the grafts. Clusters of calbindin-positive medium-sized neurons appeared only within $\mathrm{P}$ regions. Some were coextensive with the $\mathrm{P}$ regions, whereas others appeared only within subfields of the $P$ regions (see below and Figs. 5D and 9). Certain clusters of medium-sized calbindinpositive neurons were surrounded by a very pale ring, so that they formed distinct isolated patches (Fig. $5 B$ ). For other clusters, sometimes within the same graft, there was a gradient of calbindin-like immunoreactivity in the neuropil extending with diminished intensity into immediately adjoining NP regions. In all of the sections stained for calbindin-like immunoreactivity from the 14 rats, only 4 large (ca. 19-25 $\mu$ m diameter) calbindinimmunoreactive neurons were found in P regions. Two of these cells resembled in size and shape the very rare medium-large (ca. $19 \mu \mathrm{m}$ diameter) calbindin-positive cells that were found in the ventral and ventrolateral parts of the caudoputamen of the hosts.

In the AChE-poor NP regions of the grafts, medium-sized calbindin-positive cells with a morphology similar to those of the $P$ regions were extremely rare. However, multipolar calbindin-positive neurons with well-stained dendrites were prominently scattered through the NP tissue (Fig. 5, $B, G$ ). These neurons comprised a mixed population of large to mediumsized cells (ca. 13-31 $\mu \mathrm{m}$ diameter, a few up to $38 \mu \mathrm{m}$ ) cells with dendrites extending for considerable distances from the cell body and sometimes branching extensively. Spines were not detected on the dendrites. To distinguish these cells from the medium-sized calbindin-positive neurons in the $\mathrm{P}$ regions, we call them the "multipolar calbindin-positive neurons."

These multipolar calbindin-positive neurons and associated calbindin-positive neuropil appeared to form subfields within the NP zones of some grafts. In other grafts, the multipolar calbindin-positive neurons were scattered throughout most of the NP tissue, and the calbindin-positive neuropil in the NP zones was also diffusely distributed. Occasionally, well-stained processes of such multipolar calbindin-positive neurons in NP regions extended into the margins of patches of calbindin-positive medium-sized neurons in adjoining $P$ regions.

Almost no calbindin-positive multipolar neurons comparable to those in the NP regions of the grafts were present in the striatum of the hosts. However, calbindin-positive neurons with similar shapes and sizes were present in the caudal pole of the host's pallidum (ca. 13-31 $\mu \mathrm{m}$ diameter, Fig. $5 I$ ) and in the basolateral nucleus of the amygdala (ca. 14-31 $\mu \mathrm{m}$ diameter, Fig. $5 H$ ). Calbindin-positive neurons with similarly well stained dendrites but smaller size (ca. 12-31 $\mu$ m diameter, most ca. 19 $\mu \mathrm{m}$, a few up to ca. $25-31 \mu \mathrm{m}$ ) were always found in the perirhinal cortex that lies ventrolateral to the caudoputamen (Fig. $5 J)$.

In addition to NP regions rich in calbindin-positive multipolar neurons, there were fields within the NP regions of the grafts in which such neurons were absent and in which little calbindin-like immunoreactivity appeared in the neuropil. Thus, at least 3 types of tissue were identified in the transplants based on the calbindin-immunostaining: (1) tissue rich in mediumsized calbindin-positive neurons without well-stained dendrites (occurring in $\mathrm{P}$ regions); (2) tissue containing multipolar, often very large calbindin-positive neurons with prominent dendritic arbors (occurring in NP zones); and (3) tissue containing few neurons of either category (occurring both in $\mathrm{P}$ and in NP zones).

Just as the restriction of multipolar calbindin-positive cells with well-stained dendrites to NP regions was nearly absolute, 


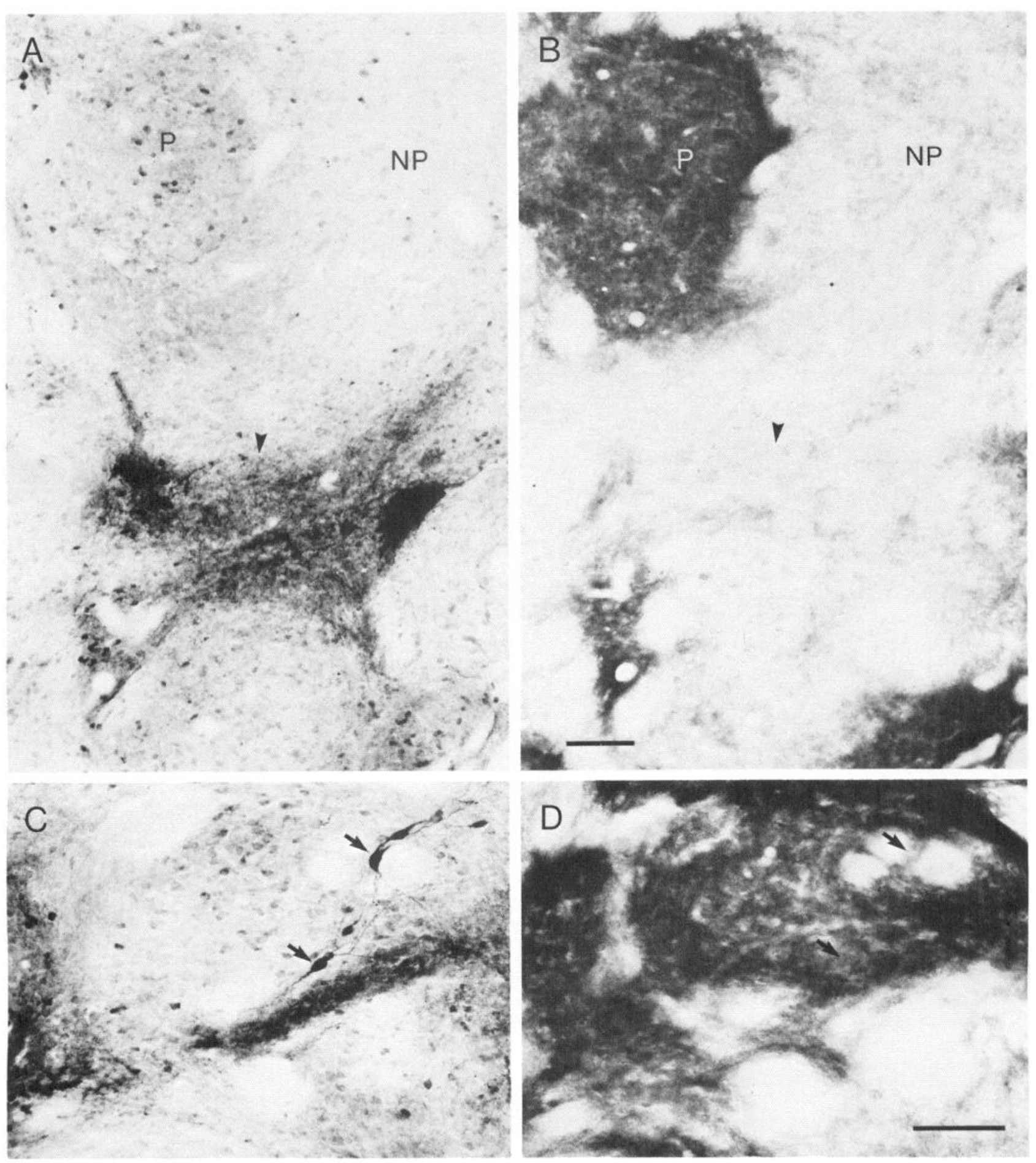

Figure 7. $A$ and $B$, Photomicrographs of corresponding fields from serially adjacent sections through graft tissue in case RSG2-23, postgraft survival 15 months, illustrating patterns of mENK-like immunoreactivity $(A)$ in relation to distribution of AChE activity $(B)$. Medium-sized mENKpositive cells appear in $\mathrm{P}$ region $(P)$ along with weakly immunoreactive neuropil. Zone of dense mENK-positive neuropil appears at arrowhead in $A$ in a nearby part of the NP tissue. Arrowhead in $B$ denotes corresponding site in AChE-stained section. Scale bar for $A$ and $B$, shown in $B$, indicates $100 \mu \mathrm{m}$. $C$ and $D$, Corresponding fields from serially adjacent sections from same case as in $A$ and $B$ stained for mENK-like immunoreactivity $(C)$ and for AChE activity $(D)$. Note, at arrows in $C, 3$ immunoreactive neurons slightly larger than the typical mENK-positive medium-sized neurons of the host striatum. They are in an AChE-rich P region (see corresponding arrows in $D$ ). Note streaks of strongly mENK-positive neuropil at the borders of the P region. Scale bar for $C$ and $D$, shown in $D$, indicates $100 \mu \mathrm{m}$.

the localization of clusters of medium-sized calbindin-positive cells within P regions was also the rule, with only 3 exceptions observed in NP regions of 3 sections (from 2 brains) of 23 sections (from 7 brains) in which AChE-stained sections serially adjoining calbindin-stained sections were available. The first was a cluster in NP containing calbindin-positive neuropil and also a few medium-sized calbindin-positive neurons. The second was an NP zone with one large calbindin-immunoreactive 


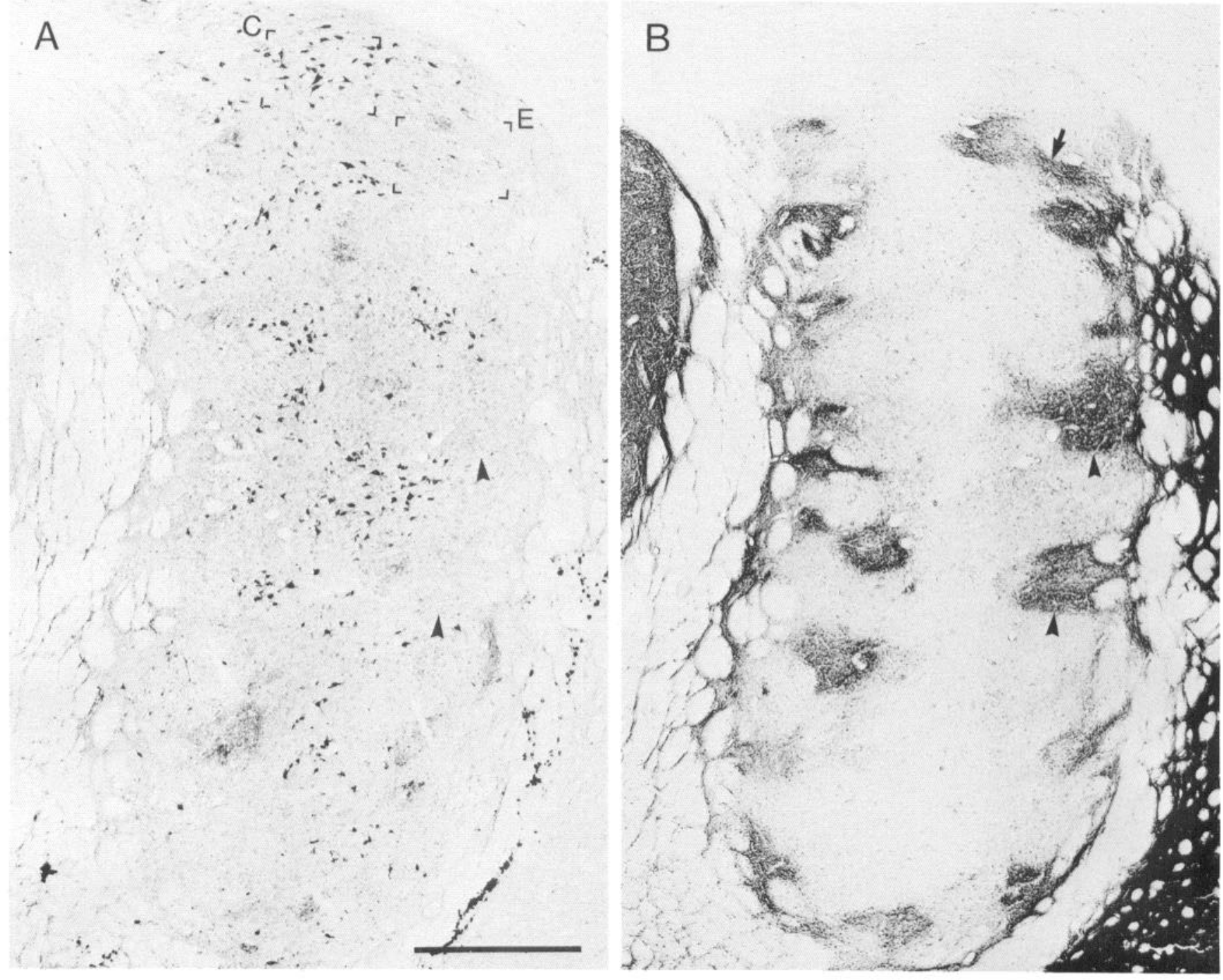

Figure 8, $A$ and $B$, Serially adjoining sections from case RSG2-17, postgraft survival 11 months, stained for SOM-like immunoreactivity $(A)$ and AChE activity $(B)$; scale bar for $A$ and $B$, shown in $A$, indicates $0.5 \mathrm{~mm}$. Arrowheads in $A$ and $B$ point to locations of $2 \mathrm{P}$ regions. Note that many medium to large SOM-positive neurons with prominent dendrites are distributed through the AChE-poor NP regions but do not occur in the P regions. Brackets in $A$ marked $C$ indicate location of field shown at higher magnification in $C$. Similar types of SOM-positive neurons present in the ventrolateral cortex of the host are shown in $D$. $E$ illustrates bracketed region in $A$ (marked by letter $E$ ), showing a single medium-sized SOMpositive cell at the margins of the $\mathrm{P}$ region in this field (location is indicated by the arrow in $B$ ). $F$, A field of SOM-positive neurons from the normal contralateral striatum of host. Scale bar for $C-F$, shown in $F$, indicates $100 \mu \mathrm{m}$.

cell but also some medium-sized calbindin-positive neurons. The third was a calbindin-positive patch rich in medium-sized immunostained neurons similar to those in the $\mathrm{P}$ regions but for which there was no AChE-positive correspondent in the adjoining section.

\section{Immunostaining for mENK-like immunoreactivity}

Like the calbindin-positive medium-sized neurons in the grafts, mENK-positive medium-sized neurons were mainly confined to $\mathrm{P}$ regions (Fig. 5, $A, C$ ). In such regions, both neuropil and medium-sized cell bodies were immunostained (Fig. $5 K$ ). The medium-sized mENK-positive neurons were similar to those of the normal host striatum (Fig. $5 L$ ). They tended to aggregate in clusters, but the clusters varied in the intensity of mENK-like immunoreactivity they expressed.

Although mENK-like immunostaining in NP regions was gen- erally much weaker than that in P regions, the immunostaining was quite heterogeneous, and some mENK-positive regions appeared within NP tissue. Some NP zones contained many small mENK-positive cells (ca. 6-10 $\mu \mathrm{m}$ ), often packed together closely (Figs. $5 C, 6$ ). Occasionally, a patch of highly mENK-immunoreactive neuropil appeared in an NP region (Fig. 7, $A, B$ ), sometimes in association with a few heavily stained mediumsized mENK-positive neurons.

A few of the intensely mENK-immunoreactive neurons in the graft had diameters slightly to considerably larger than mENK-positive medium-sized neurons of the normal host striatum (ca. 18-31 $\mu \mathrm{m}$ diameter versus ca. 13-15 $\mu \mathrm{m}$ diameter in our sample). These mENK-positive neurons had well-stained dendrites that lacked the densely spiny character of the mENKpositive neurons of normal striatum. The largest of the group (ca. $31 \mu \mathrm{m}$ diameter) was about the same size and shape as the 

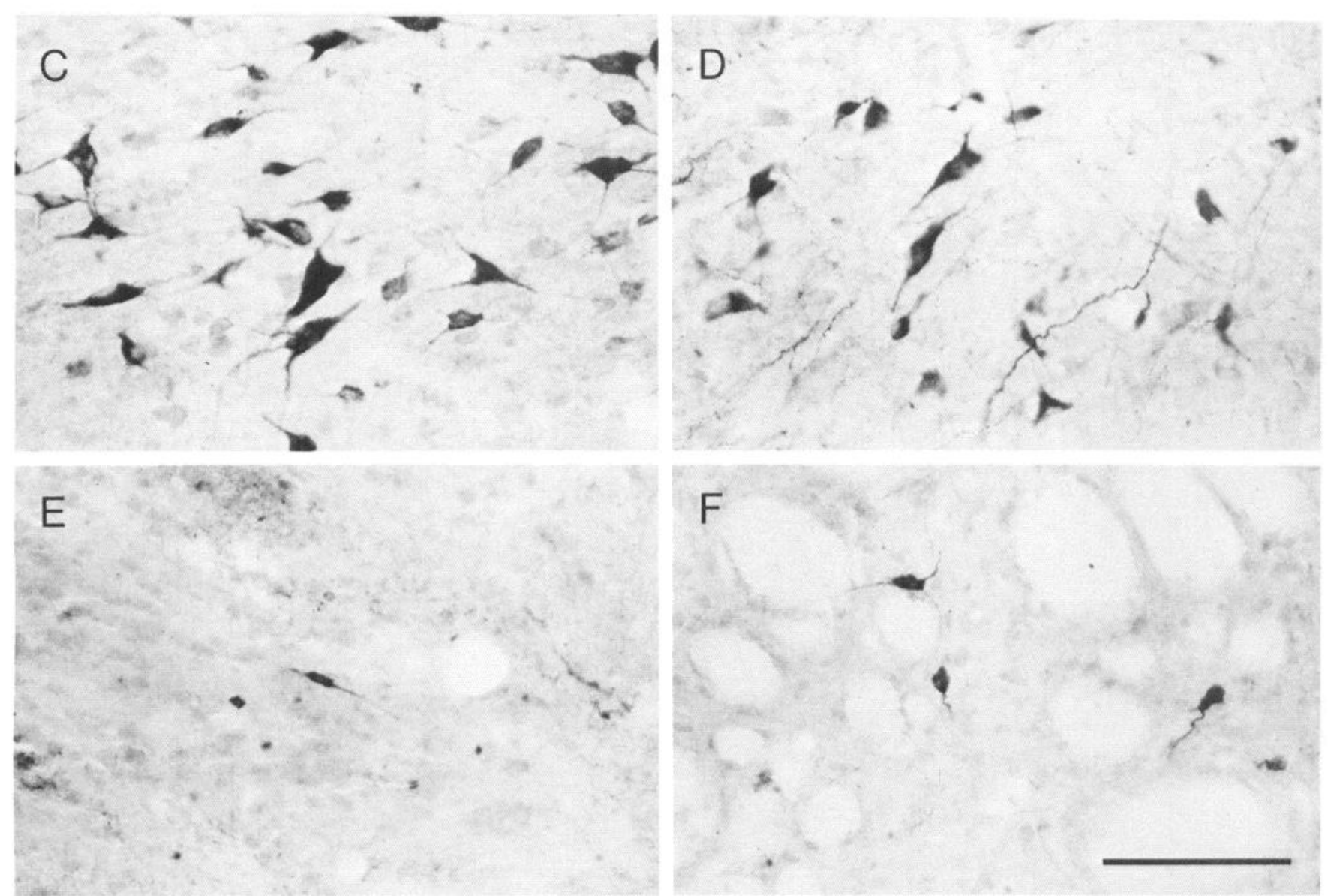

Figure 8. Continued.

cholinergic interneurons of the rat's striatum. These mENKpositive neurons were nearly all associated with zones of neuropil expressing intense mENK-like immunoreactivity (Fig. 7C). Thus, patches of intensely mENK-positive neuropil occurred both in $\mathrm{P}$ zones (Fig. 7, $C, D$ ) and in NP zones. Interestingly, some of the mENK-rich NP zones had detectable, though weak, AChE activity (see Fig. 5, $A, C$ ). Patches of mENK-positive neuropil in register with zones of relatively weak $\mathrm{AChE}$ activity normally occur in the ventral caudoputamen of the rat at rostral levels (see Fig. 11, $B, C$ ).

\section{Immunostaining for SOM-like immunoreactivity}

Many large and medium-sized SOM-positive neurons (ca. 13$31 \mu \mathrm{m}$ diameter, a few up to ca. $38-44 \mu \mathrm{m}$ ) were located in the NP regions of the transplants (Fig. 8, $A-C$ ). By contrast, few SOMpositive neurons appeared within the AChE-rich $\mathrm{P}$ regions (Fig. $8 E$ ), and these were similar in size to the SOM-positive neurons of the normal host striatum (Fig. $8 F$ ). The large SOM-positive neurons in the NP regions (Fig. $8 \mathrm{C}$ ) were larger than the SOMpositive neurons of the normal host striatum (Fig. $8 F$ ). Medium to large SOM-positive neurons (ca. 13-34 $\mu \mathrm{m}$ diameter) were common in the cortex of the host brains, especially ventrolaterally (Fig. $8 D$ ), but none were as large as the largest SOMpositive neurons in the NP regions of the grafts.
Expression of markers for striosomal and matrical tissue in the AChE-rich $P$ regions of the grafts

Calbindin-like and mENK-like immunoreactivities are normally expressed by medium-sized neurons of the striatal matrix at maturity, and during much of the postnatal development, and either are not expressed normally by striosomal neurons (calbindin, Gerfen et al., 1985, 1987b; F.-C. Liu et al., unpublished observations) or are less consistently and intensely expressed by striosomal neurons (mENK, Graybiel and Chesselet, 1984a, b; Besson et al., 1986, 1988b). Neither calbindin-like immunoreactivity nor mENK-like immunoreactivity is a secure indicator that a striatal neuron is matrical, however, because calbindin-positive neurons are absent altogether in the dorsolateral striatum, and mENK immunoreactivity is detectable in some striosomal neurons. Nevertheless, the combination of the two markers within a given zone of the graft would strongly suggest that the zone corresponds to matrix tissue or at least to tissue expressing markers characteristic of matrix tissue at maturity and during much of postnatal development. The best marker for putative striosomes in the mature rat's striatum and in the developing rat's striatum after about P2-P3 is ligand binding for mu opioid receptors (Herkenham and Pert, 1981; van der Kooy, 1984; Moon Edley and Herkenham, 1984). To 

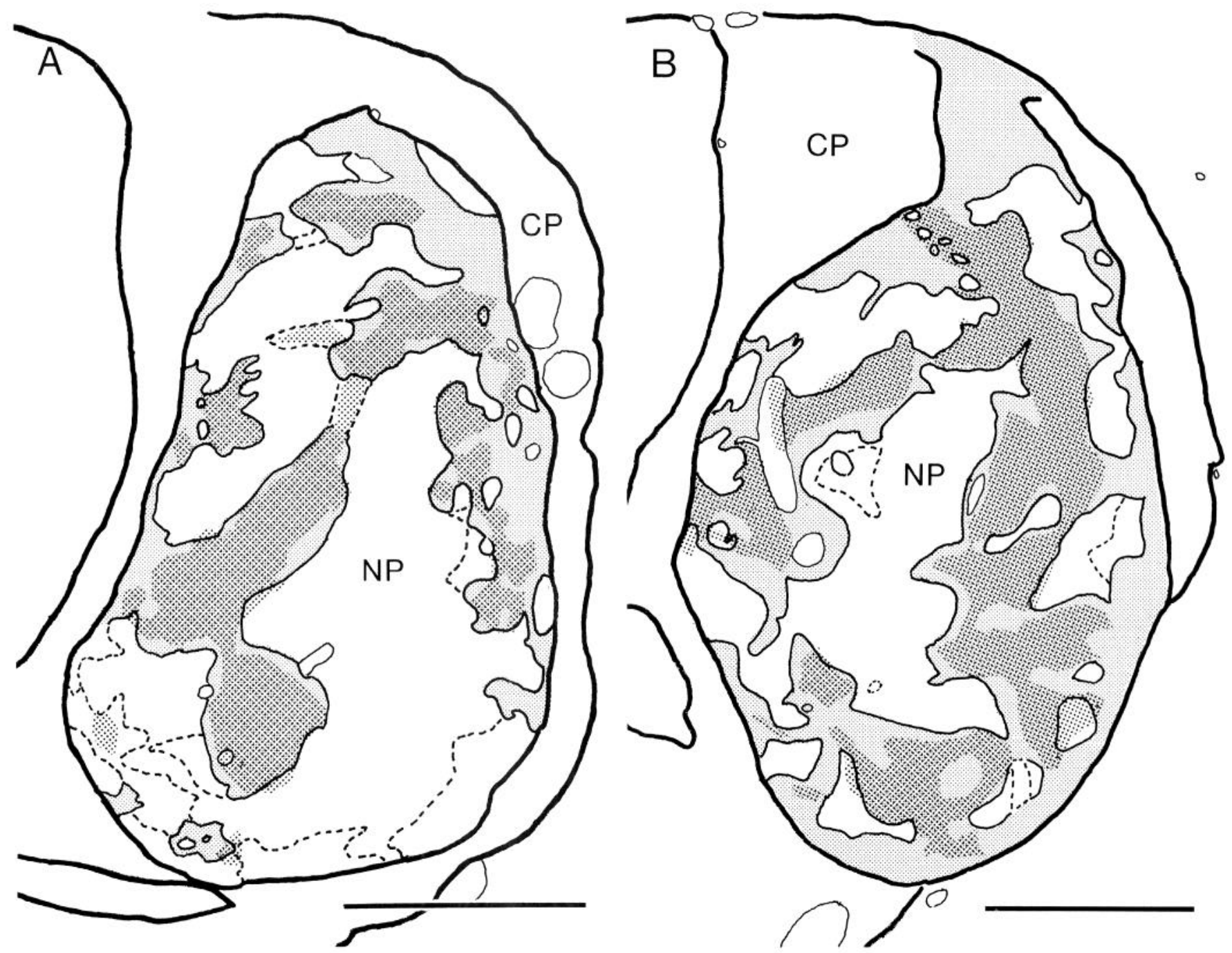

Figure 9. Schematic overlay drawings illustrating relative distributions of the AChE-rich P regions (light stipple) and the clusters of calbindinpositive medium-sized neurons (dark stipple) observed in serially adjoining sections from 2 different cases $(A$, RSG2-21, postgraft survival 13 months; $B$, RSG2-32, postgraft survival 12 months). Note that for some $\mathrm{P}$ regions, the calbindin-positive cell clusters and AChE-rich zones share nearly the same space. For other P regions, the patches of calbindin-positive medium-sized neurons form subfields within the AChE-rich P regions. Fine lines indicate borders of blood vessels; dashed lines indicate zones of weak AChE activity. Scale bars, $1 \mathrm{~mm}$.

determine whether the AChE-rich $\mathrm{P}$ regions of the grafts contained markers of striosomal tissue or of matrical tissue, or both, we therefore carried out detailed serial section comparisons of the patterns of immunostaining for calbindin-like and mENKlike immunoreactivity in relation to the distribution of $\mathrm{AChE}$ staining and compared these to the distribution of binding sites for ${ }^{3} \mathrm{H}$-naloxone, a marker for mu opioid receptors. Typical findings are illustrated in Figures 5, $A-D$, and Figures 9-11.

Nearly every patch of medium-sized calbindin-positive cells and mENK-positive cells clearly fell within an AChE-positive $P$ region identified in serial sections, and for the most part the calbindin-positive medium-cell clusters and mENK-positive medium-cell clusters were in close serial section alignment. For some $\mathrm{P}$ regions, the size, shape, and location of the clusters of medium-sized cells seen with the calbindin and mENK antisera were nearly identical to those of the AChE-positive regions (Fig. 9A). In other instances, however, the $\mathrm{P}$ regions were larger than the calbindin-positive or mENK-positive medium-sized cell patches they overlapped with, even when the zones of $\mathrm{AChE}$ staining and of calbindin or mENK staining shared some borders (Figs. 5D, 9). Thus some AChE-positive $\mathrm{P}$ regions of the grafts corresponded to zones of high calbindin-like and mENKlike immunoreactivity, whereas other $\mathrm{P}$ regions contained subfields expressing these striatal matrix markers and subfields lacking them. We found no instances in which the calbindin-positive or mENK-positive medium-sized cell clusters were larger than the corresponding AChE-positive $\mathrm{P}$ zones.

In all 5 brains in which sections were processed for ${ }^{3} \mathrm{H}$-naloxone binding, typical opiate receptor patches appeared in the host striatum. However, in only one of the grafts was ${ }^{3} \mathrm{H}$-naloxone binding above background levels. In this graft (Fig. 10), the one fresh-frozen specimen, much of the binding was diffuse. Even where the binding was not uniform, it lacked the crisp modularity of ${ }^{3} \mathrm{H}$-naloxone binding characteristic of the normal striatum of the adult rat. Only one small patch of intense binding, visible in films of several closely spaced sections, and a few regions of slightly heightened binding were present. The patch of most intense binding was in a $\mathrm{P}$ region, but the other regions 

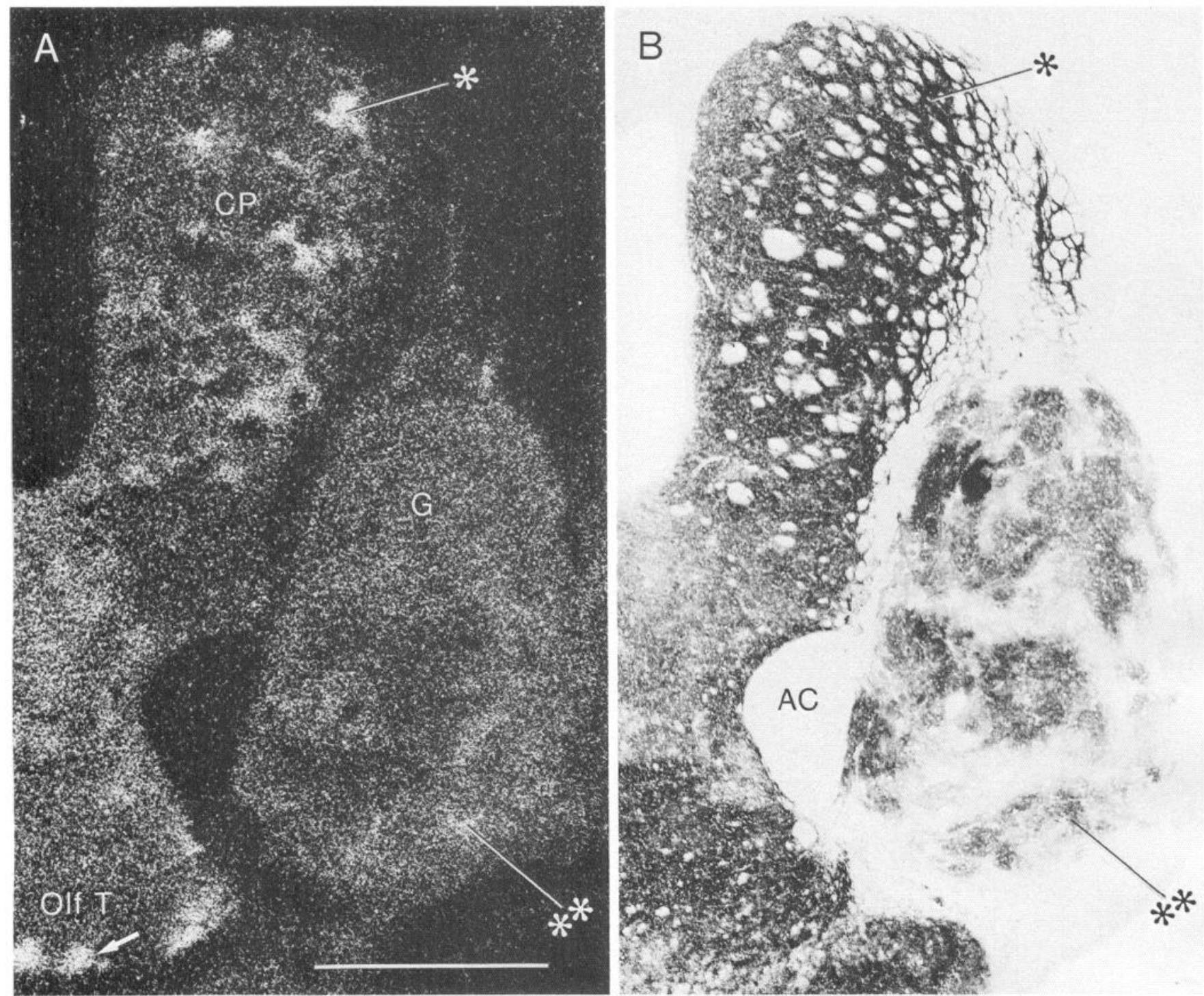

Figure 10. A, Photograph of film autoradiogram illustrating ${ }^{3} \mathrm{H}$-naloxone binding in host striatum $(C P)$ and in adjacent tissue of fetal striatal graft $(G)$ in case RSG2-34, postgraft survival 12 months, processed fresh-frozen. $B$, Adjacent section stained for AchE to illustrate locations of $\mathrm{P}$ and NP regions in the graft. Asterisk in $A$ indicates one of the patches of dense ${ }^{3} \mathrm{H}$-naloxone binding (putative striosomes) in host striatum. Asterisk in $B$ marks same site in AChE-stained section; note that the patch is not identifiable as AChE-poor zone. Arrow in $A$ marks dense patch of ${ }^{3} \mathrm{H}$-naloxone binding in olfactory tubercle of host. In the graft, only 1 crisp zone of heightened ${ }^{3} \mathrm{H}$-naloxone binding is visible (double asterisks). As shown by matching double asterisks in $B$, it is in a $\mathrm{P}$ region. $A C$, anterior commissure. Scale bar for $A$ and $B$, shown in $A$, indicates $1 \mathrm{~mm}$.

of heightened binding were in NP zones (compare Fig. 10, $\mathrm{A}$ and $B$ ). Some zones of especially impoverished binding appeared in the graft, both in $\mathrm{P}$ and in NP regions. In the normal adult striatum, such zones occur in the matrix (Fig. 10A).

The 4 remaining perfused brains had normal patterns of ${ }^{3} \mathrm{H}$ naloxone binding in the host tissue but almost no ${ }^{3} \mathrm{H}$-naloxone binding in the grafts (Fig. 11A). The grafts contained patches of opioid peptide (mENK-like) immunoreactivity (Fig. 11C), and the patches of medium-sized mENK-positive cells fell within AChE-rich $\mathrm{P}$ regions (Fig. 11, B, C). In all of the grafts, donor cells had been exposed to ${ }^{3} \mathrm{H}$-thymidine, but at the exposure times used for the ${ }^{3} \mathrm{H}$-naloxone binding, ${ }^{3} \mathrm{H}$-thymidine labeling did not interfere with interpretation of the sparse autoradiographic labeling visible in the films (cf. Nastuk and Graybiel, 1985). The low levels of grain in the graft tissue were similar to those in nearby nonstriatal grey matter.

\section{Discussion}

The observations reported here confirm the presence of a macroscopic modular architecture in fetal striatal grafts and a remarkable phenotypic resemblance of many neuronal constituents in the grafts to neuronal constituents found in normal postnatal and mature striatum (Isacson et al., 1984, 1985, 1987; Pritzel et al., 1986; Walker et al., 1987; Deckel and Robinson, 1987; Sanberg et al., 1987; Graybiel et al., 1987a; Clarke et al., 1988; Roberts and DiFiglia, 1988; DiFiglia et al., 1988). The phenotypic resemblance inferred from the markers screened does not necessarily imply identity but does suggest that at the cellular level many antigen characteristics expressed by neurons in the grafts were like those expressed by neurons in normal striatal tissue. Unexpectedly, however, our experiments raise the possibility that the compartmental architecture of the grafts may 

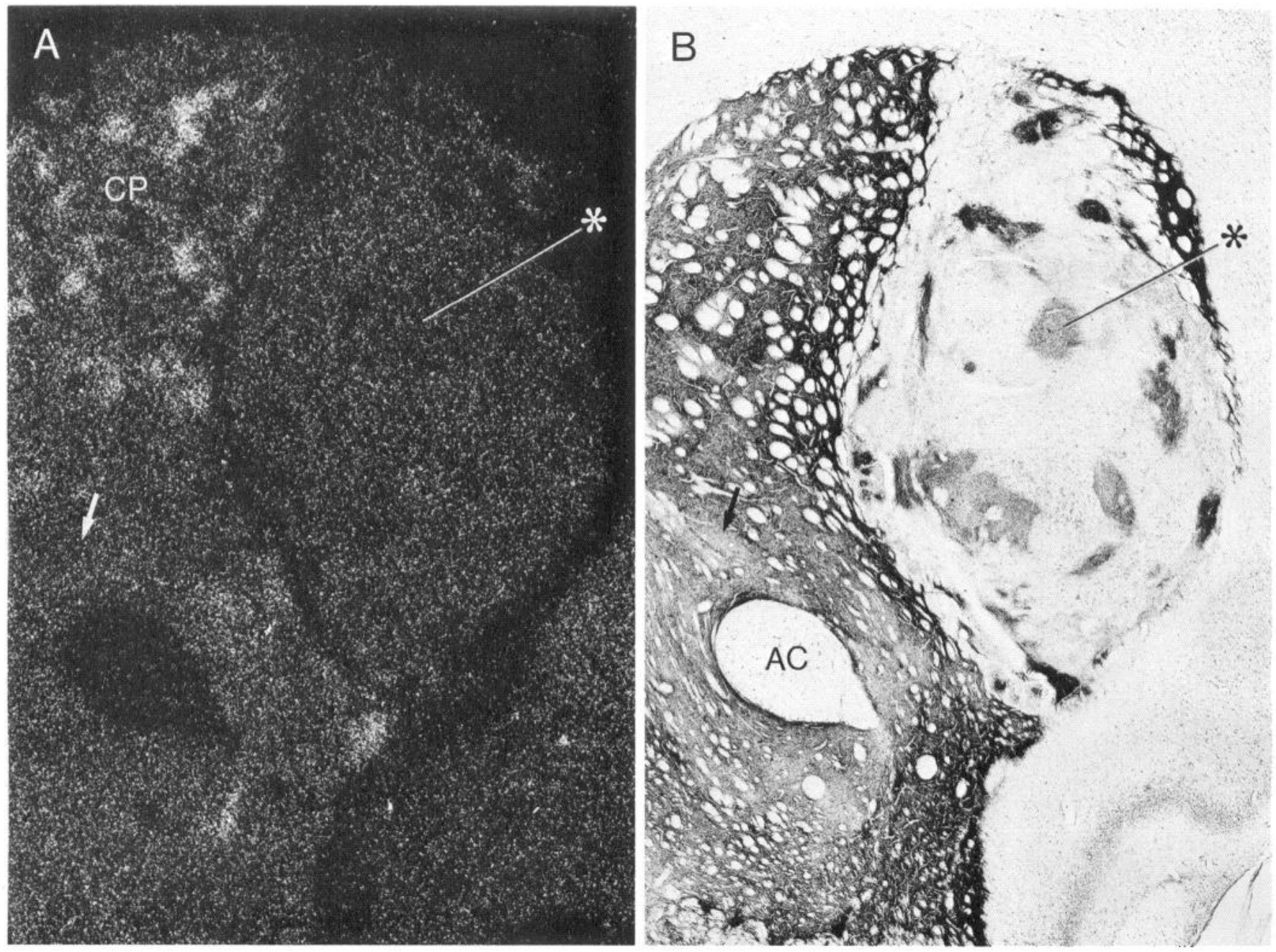

Figure 11. Patterns of $(A){ }^{3} \mathrm{H}$-naloxone binding in film autoradiogram, $(B)$ AchE activity, and $(C)$ mENK-like immunoreactivity in graft tissue of case RSG2-30, postgraft survival 16 months. $A$, Patches of ${ }^{3} \mathrm{H}$-naloxone binding are visible in host's striatum $(C P)$ but not in graft. $B$, Slight heterogeneity of AChE activity visible in host's striatum (including ventral AChE-poor zone at arrow), and typical AChE-rich P zones (example at asterisk) embedded in fields of AChE-poor NP tissue in the graft. $C$, Heterogeneity of mENK immunostaining in host's striatum, including patch of mENK-rich neuropil at arrow matching AChE-poor zone at arrow in $B$. In graft, zones of high and low mENK immunoreactivity occur, including mENK-rich zone at asterisk corresponding to $\mathrm{P}$ zone marked by asterisk in $B$. $A C$, anterior commissure. Scale bar for $A-C$, shown in $C$ indicates $1 \mathrm{~mm}$.

be quite different from that seen in the normal striatum. Our results suggest that the AChE-rich patches in fetal striatal grafts may represent islands of striatal tissue surrounded by cells lacking the phenotypy of mature striatum and that at least part of the tissue of these islands, rather than being striosomal, actually might be matrical in type. The phenotypy of the AChE-poor NP zones was not definitively determined, but the evidence suggests that these may be comprised of nonstriatal tissue or, perhaps, of an admixture of tissue resembling immature striatal tissue and some nonstriatal cells. The experiments did not resolve the question of whether the tissues of the $\mathrm{P}$ and NP regions were mature or immature in phenotypy. As discussed below, however, the evidence tends to favor a degree of maturation for at least the $\mathrm{P}$ regions of near or greater than the immediate perinatal stage.

\section{Donor-cell distributions}

The results of the ${ }^{3} \mathrm{H}$-thymidine experiments argue against the hypothesis that the modular arrangement of $\mathrm{P}$ and $\mathrm{NP}$ zones in the grafts reflects the separation of compartments made up exclusively of host and of donor tissue, respectively. Some donor cells, marked by ${ }^{3} \mathrm{H}$-thymidine, appeared both in the AChErich $\mathrm{P}$ and in the AChE-poor NP compartments. The absence of labeled neurons in the adjacent host tissue agrees with the report of McAllister (1987) and suggests that large numbers of grafted cells were not incorporated into the adjacent host tissues or, if they were initially, that they did not survive. Because cells of host origin were not experimentally labeled, we cannot exclude the possibility that some cells in the grafts were actually derived from the host or that part or even most of the patchiness of the grafts resulted from segregation of donor tissue from host tissue.

If there were a mixture of host and donor tissue in the grafts, it seems reasonable to suppose that it would be the $\mathrm{P}$ zones, not the NP zones, that were derived from the host. Almost certainly, it would be mainly striatal tissue of the host that would become mixed with donor tissue at the time of grafting, and it is the $\mathrm{P}$ regions that most resemble the host's striatal tissue. Any such 


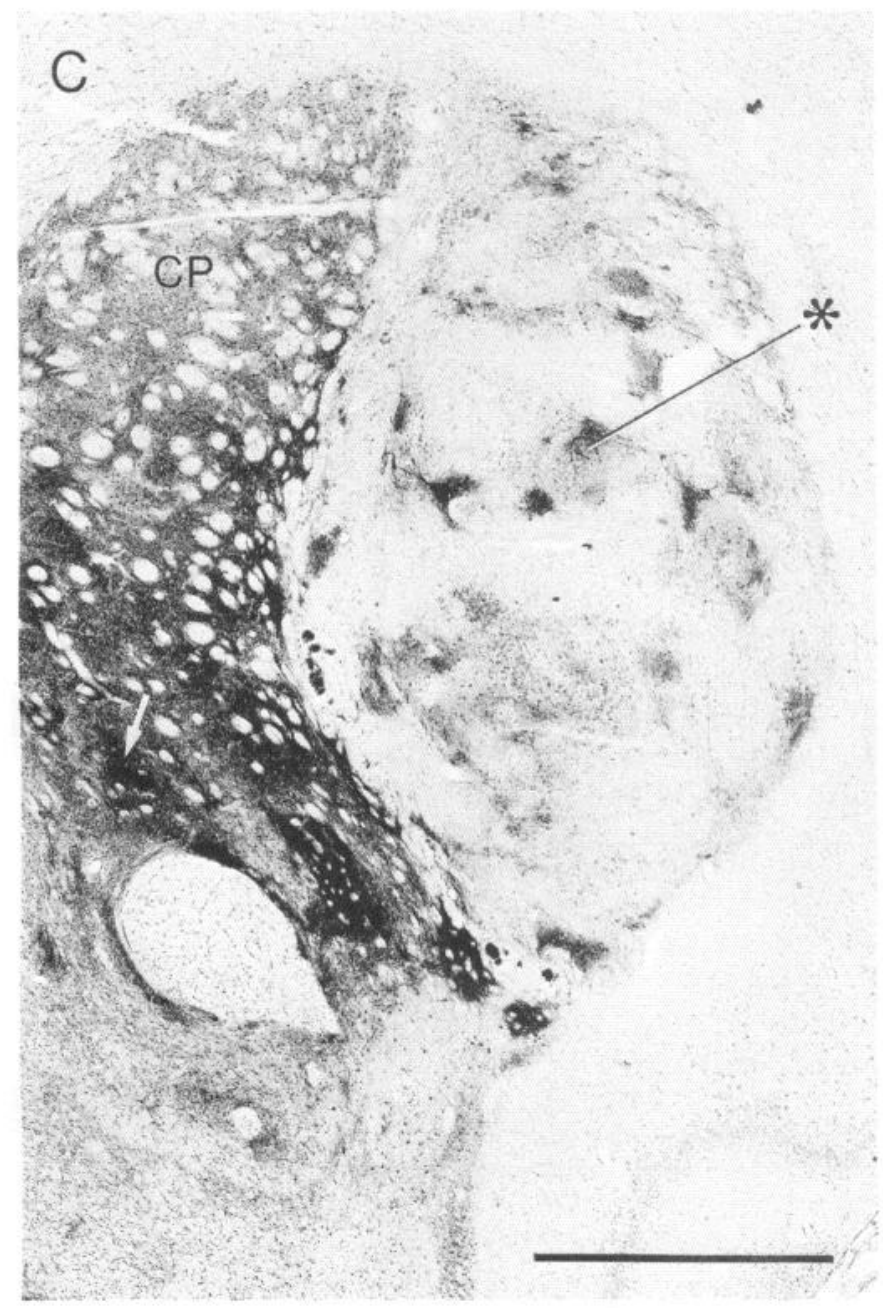

Figure 11. Continued.

host neurons in the grafts would have had to survive the toxic effects of the ibotenic acid injections (Coyle and Schwarcz, 1976; Köhler and Schwarcz, 1983; Isacson et al., 1987; Walker et al., 1987), which we confirmed in the control nongraft animal. It should be noted that Isacson et al. (1987) observed AChE-rich regions embedded in AChE-poor tissue in transplants placed outside the striatum, for example, in the substantia nigra and globus pallidus.

The E13-E15 ${ }^{3} \mathrm{H}$-thymidine exposure times were within the window of peak neurogenesis for neurons destined to inhabit striosomes (van der Kooy and Fishell, 1987). As the donor tissues were taken at E15, they could not be exposed during the reported window of peak neurogenesis for cells of the matrix, E18-E20 (van der Kooy and Fishell, 1987). This schedule of neurogenesis suggests that many if not most of the heavily labeled neurons would have been striosomal progenitors, but there is overlap between the birth dates of striosomal and matrical cell populations. Accordingly, the labeled neurons in the grafts could not be identified unequivocally as being either of striosome or matrix type despite the E13-E15 exposure times. Many neurons of the cerebral cortex (and other forebrain regions) are also born during the E13-E15 time period, including many neurons in tissue ventral and lateral to the striatum (e.g., van der Kooy and Fishell, 1987). Some of these neurons may derive from the ganglionic eminence (see below). Consequently, neurons in the grafts labeled with ${ }^{3} \mathrm{H}$-thymidine could not be identified positively as striatal.

\section{Nature of the AChE-rich $P$ regions}

The present study, together with previous reports (Pritzel et al., 1986; Isacson et al., 1987; Walker et al., 1987; Wictorin et al., 1988), leaves little doubt that the AChE-rich P regions comprise striatal tissue. With only one exception ( ${ }^{3} \mathrm{H}$-naloxone) discussed below, every marker we employed to detect transmitter-related compounds enriched in normal mature striatal tissue had a heightened representation in the $\mathrm{P}$ regions relative to the NP regions of the grafts. Conversely, neuronal types uncharacteristic of normal mature striatum were absent or nearly absent from the $\mathrm{P}$ regions but were present in NP tissue.

In our analysis of the AChE-rich $\mathrm{P}$ regions, we found two main patterns. Some clusters of medium-sized calbindin-positive neurons were coextensive with AChE-rich tissue defining the $\mathrm{P}$ regions. Calbindin is selectively expressed in mediumsized matrix neurons at maturity and, as discussed below, available evidence suggests that this antigen is also expressed in the matrix developmentally, during the early postnatal period. Clearly, for calbindin-like immunoreactivity as for other markers used in this study, we cannot be sure that the expression of the marker would be identical in the transplants and in normal striatum of any age. Nevertheless, this evidence is compatible with the view that some $\mathrm{P}$ regions were mainly matrical.

For other $\mathrm{P}$ regions, the calbindin immunostaining of medium-sized neurons was limited to subregions of the AChE-rich $\mathrm{P}$ zones. This evidence suggests that some $\mathrm{P}$ regions were composed of more than one type of striatal tissue, matrix (calbindinpositive) tissue and calbindin-negative tissue that either was dorsolateral or lateral striatum (not normally calbindin-positive) or was striosomal in nature or did not, through incomplete development or other causes, express a full repertoire of antigens characteristic of mature striatal neurons. We stress that a few calbindin-immunoreactive neurons may occur in striosomes in the normal striatum and that the presence of a few calbindinnegative neurons in matrix has not been excluded (Gerfen et al., 1985; present observations). In the one case in which $\mathrm{mENK}$ immunostaining was available in sections immediately adjacent to those stained for calbindin-like immunoreactivity, the clusters of mENK-positive medium-sized neurons overlapped the calbindin-positive medium-sized cell clusters but sometimes were larger (although still within the AChE-rich $\mathrm{P}$ regions). This correlative evidence suggests that at least some of the neurons in the calbindin-negative parts of the $\mathrm{P}$ regions may have more closely resembled striosomal neurons than dorsolateral matrix neurons, because medium-sized neurons in the dorsolateral mature matrix do express mENK-like immunoreactivity, whereas not all calbindin-negative striosomes are rich in strongly mENKimmunoreactive neurons.

Opioid receptor-related ligand binding was only rarely aggregated into strongly labeled patches in the grafts, even though intensely labeled ${ }^{3} \mathrm{H}$-naloxone-positive patches (striosomes) could be detected in the immediately adjacent host striatum. Thus, although characteristic matrix markers were absent in parts of certain $\mathrm{P}$ zones, the ${ }^{3} \mathrm{H}$-naloxone binding did not provide evidence for dense concentrations of striosomal tissue in these subfields. The strongest binding observed in graft tissue was in the unperfused brain, but in the perfused brains there 
was intense ${ }^{3} \mathrm{H}$-naloxone binding in host tissue adjoining the grafts having very little detectable binding. It therefore seems unlikely that the low binding resulted from a technical problem. Conceivably, striosomal cells in the $P$ regions had down-regulated receptor numbers or were mixed with larger matrix-cell populations in numbers too small to detect. The limited development of patches of dense ${ }^{3} \mathrm{H}$-naloxone binding observed is directly comparable to the findings of Lanca et al. (1986). Isacson et al. (1987) observed ${ }^{3} \mathrm{H}$-diprenorphine-positive patches within their series of grafts, but these were clearly smaller than the AChE-positive patches. These investigators also found other characteristic constituents of striosomes in the AChE-positive patches, such as mENK-positive fibers and SP-positive cell bodies, further suggesting that AChE-rich regions of fetal striatal grafts can also contain striosomal tissue.

The apparent predominance of matrical markers in the $P$ regions in the present series of grafts is interesting given the larger proportion of striosomal than matrical tissue that should have been present in the donor caudoputamen at the time of dissection (E15). However, a larger fraction of progenitors of matrical cells should have been present in the germinal epithelium at the time of dissection (van der Kooy and Fishell, 1987), and these could have survived and developed preferentially. When all the findings so far available are considered together, it seems likely that markers characteristic of both striosomes and matrix can be concentrated in the AChE-rich $\mathrm{P}$ zones of striatal grafts but that their relative proportions may vary depending on slight differences in the methods of dissection and of tissue preparation.

\section{Nature of the AChE-poor NP regions}

One of the most clear-cut findings of the present study was the presence in the NP regions of many large multipolar calbindinpositive neurons and SOM-positive neurons that were unlike any found in the host striatum but that resembled neurons found elsewhere in the host's forebrain. We did not test for cellular colocalization of the calbindin and SOM antigens. Even if the two antibodies singled out the same populations of cells, however, the findings with each argue strongly that neuronal types not found in mature striatum were widely distributed in the AChE-poor NP regions. Neurons larger than those of the normal striatum have been observed previously in striatal grafts prepared both from embryonic (DiFiglia et al., 1988) and from neonatal striatal tissue (McGeer et al., 1984). DiFiglia et al. (1988), Roberts and DiFiglia (1988), and Walker et al. (1987) have also noted other morphological characteristics of fetal striatal grafts that differ from those of normal striatum. Unfortunately, it is not clear whether the unusual characteristics they observed were associated with cells of what we here call $P$ regions and consider striatal in nature or were characteristic of NP regions.

The large multipolar calbindin-positive neurons found in the prcsent scrics of grafts closcly rcsembled those of the caudal (but not rostral) pallidum, the basolateral amygdala, and the ventrolateral cortex of the hosts. The possibility of pallidal contamination of fetal striatal grafts has been discussed in several previous reports (Walker et al., 1987; Isacson et al., 1987; DiFiglia et al., 1988). Our own evidence based on calbindin immunohistochemistry makes this an attractive possibility at least for caudal pallidal tissue. The results of EGF-like immunohistochemistry suggest that the neuropil of the graft tissue did not express the EGF-like staining typical of normal mature pallidum (Fallon et al., 1984), but because EGF-like immunoreactivity is confined to pallidal neuropil, we could not judge perikarya. The basolateral nucleus of the amygdala is rich in AChE activity, unlike the NP regions. Because most of the AChE in the basolateral nucleus is thought to be contained in afferent fibers (Emson et al., 1979), however, this does not necessarily detract from the possibility that the multipolar calbindin-positive neurons of the grafts represented amygdaloid neurons. The diameters of some of the multipolar calbindin-positive neurons in the NP regions were larger than those of calbindin-positive neurons in the cortex, but their appearance was otherwise reminiscent of the multipolar calbindin-positive cells of the ventrolateral cortex of the hosts.

The SOM-positive cells of the NP regions similarly resembled SOM-positive neurons in the host cortex, both ventrally and elsewhere, again except that some of the SOM-positive neurons in the grafts were larger than those in the cortex. Interestingly, the distribution of neurons in the grafts expressing cholinergic markers (F.-C. Liu et al., unpublished observations; Graybiel et al., 1987a) suggests that the large neurons of the NP regions are not cholinergic. Most large choline acetyltransferase-positive and $\mathrm{AChE}$-positive neurons lie in $\mathrm{P}$ regions.

A reasonable explanation for the occurrence in the grafts of neurons similar to those of the caudal pallidum, basolateral amygdala, and cortical plate is that cells destined to have these phenotypes were included within the tissue dissected to prepare the "striatal" cell suspensions. The pallidum and basolateral amygdala both physically adjoin the striatum ventrolaterally, and the ventrolateral cortex lies just beyond these tissues. An attractive hypothesis suggested by our findings is that some of the progenitor cells giving rise to these tissues may lie in the ganglionic eminence and migrate out through the striatal anlage.

An alternative interpretation is that such neuronal constituents, although uncharacteristic of mature striatum, may normally appear in immature striatum and that the grafts, as suggested by Isacson et al. (1987), may have the phenotypy of immature striatum. In fact, as discussed in the next section, in a study of the postnatal development of the rat striatum (F.-C. Liu et al., unpublished observations), we have observed large calbindin-positive neurons with widely ramified dendritic arbors in the perinatal striatum but have not observed large multipolar SOM-positive cells similar to those of NP regions.

A third possibility to be considered is that under the abnormal conditions of the transplant's environment, striatal progenitor cells (or other progenitor cells) could have been transformed into neurons with characteristics not found normally in the striatum. Whether the large multipolar calbindin-positive and SOM-positive cells represented immature or transformed striatal neurons or other neurons, there remains the question of why, in the grafts, they were commonly found in NP regions but almost never found in immediately adjoining $P$ regions.

The large multipolar calbindin-positive and SOM-positive cells were not the only cells in the NP regions that were unlike host striatal neurons. In sections stained for mENK-like immunoreactivity, we also found NP zones containing groups of mENK-positive cells that were smaller than medium-spiny striatal neurons.

In summary, 3 types of cells with phenotypy unlike that of cells in host striatum were detected in NP (but almost never in P) regions of the grafts. The AChE-poor NP regions did not, however, express high levels of transmitter-related compounds 
typical of mature striatum and, according to available evidence, of much of striatum during postnatal development.

\section{Developmental status of the grafts}

A natural interpretation of the compartmentalization of fetal striatal grafts, given their appearance in AChE-stained sections, is that the AChE-rich zones are immature striosomes embedded in immature matrix tissue (Isacson et al., 1987). As first noted by Isacson et al. (1987), a number of characteristics of the grafts in addition to their AChE-positive patches could also be taken to suggest their immaturity. Here, as well, we found such characteristics: there were patches of mENK-like immunoreactivity coincident with AChE staining (Graybiel et al., 1981); there was diffuse mu opioid receptor-related binding in the grafts (Kent et al., 1982; van der Kooy, 1984; Lanca et al., 1986); and E13labeled ${ }^{3} \mathrm{H}$-thymidine-positive neurons were relatively diffusely distributed through the grafts (van der Kooy and Fishell, 1987). Other evidence, however, highlights the difficulty of determining with certainty the developmental status of the graft tissue. Nearly all available markers for identifying the striosomal and matrix compartments undergo pronounced developmental shifts in expression occurring at different times in different striatal regions, and their expression tends to be graded across development and across compartments. For some markers, there are special problems in making inferences from species to species. For example, in the newborn rat, as in other neonatal mammals, $\mathrm{AChE}$ is expressed more strongly in the neuropil of future striosomes than in the neuropil of future matrix, but at adulthood, when the relative staining densities of the striosomes and matrix are reversed in most other mammalian species, not all "striosomes" as identified by mu opioid ligand binding in the rat arc obviously more weakly stained for $\mathrm{AChE}$ than the surrounding "matrix," even with optimal staining. Therefore, in a novel tissue preparation, such as a fetal striatal graft, an AChE-positive patch in a paler surround is not necessarily an immature striosome. It could equally be a patch of either mature striosome or mature matrix tissue. Moreover, during the progressive expression of AChE activity in the striatum (of the rat and other species), there are dorsoventral and mediolateral gradients in expression, so that even in a single section not all sites of future striosomes (as identified with another marker) have enhanced AChE staining relative to future matrix. Therefore, a zone of weak $\mathrm{AChE}$ staining might conceivably represent immature striosomal tissue rather than immature matrix tissue.

Despite these limitations, the combinations of markers we screened, and information about the TH-immunostaining and catecholaminergic fluorescence in the grafts (Isacson et al., 1987; Pritzel et al., 1986; Graybiel et al., 1987a; F.-C. Liu et al., unpublished observations), taken together with information about marker expression in perinatal striatum (Specht et al., 1981a, b; Shiosaka et al., 1982; Armstrong et al., 1987; Voorn et al., 1988; F.-C. Liu et al., unpublished observations), suggest certain bounds for the maturational development of striatal tissue with marker profiles similar to tissue in the striatal transplants.

\section{The P regions}

Calbindin-like immunoreactivity is expressed in the rat's striatum by the time of birth (F.-C. Liu et al., unpublished observations). If the grafts were arrested at an early stage of development, then judging from the medium-sized perikaryal calbindin immunostaining, the developmental stage would probably be at least perinatal for the calbindin-positive part of the $P$ regions. The calbindin antigen is expressed along a ventrocaudal to dorsomedial gradient during the perinatal period (F.-C. Liu et al., unpublished observations), whereas strong $\mathrm{AChE}$ staining is expressed dorsolaterally. In fact, in the early postnatal period, calbindin-positive medium-sized cells appear only ventrocaudally, whereas AChE-positive patches appear mainly dorsally. Thus, an AChE-positive, calbindin-positive patch (typical $P$ zone) should indicate a maturational stage advanced enough for the two markers to overlap. For most of the caudoputamen (all but its caudal part), this would be a stage later than P3 and for some parts later than P7.

The appearance of mENK-immunoreactivity and SOM-immunoreactivity in medium-sized neurons in the $P$ regions supports the suggestion based on calbindin immunostaining that the $\mathrm{P}$ zones are at least at a perinatal level of development. The expression of perikaryal mENK-like immunoreactivity in medium-sized striatal neurons follows a ventrocaudal to dorsomedial developmental gradient of expression and becomes detectable throughout the striatum only postnatally. According to Shiosaka et al. (1982), SOM-like immunoreactivity is first expressed in striatal neurons at E19, and typical SOM-immunoreactive neurons become more prominent postnatally (Shiosaka et al., 1982; F.-C. Liu et al., unpublished observations).

By a P2-P3 stage of striatal development, the grafts should have had intense mu opioid ligand binding in parts comparable to striosomes and weak binding in parts comparable to matrix (Kent et al., 1982). The weak binding in P zones would be compatible with these zones as being like either early postnatal or more mature matrix. If the paucity of ${ }^{3} \mathrm{H}$-naloxone binding is interpreted as mcaning that the $P$ zones were immature, they could not be less mature in phenotypy than the stage indicated by the calbindin-like immunoreactivity of medium-sized neurons in these zones.

\section{The NP regions}

The present findings confirm Isacson et al.'s (1987) demonstration of low expression of a number of neurotransmitter-related markers in what here are called the NP regions of the grafts. We detected minimal mENK-like and calbindin-like immunostaining of medium-sized neurons, low AChE-staining, and, as just noted, little mu opioid receptor ligand binding. As we will describe in the second paper of this series, we also found little TH-like immunoreactivity in the NP zones, in agreement with the observations of Isacson et al. (1987; see also Pritzel et al., 1986; Graybiel et al., 1987a), and we found relatively few AChE-positive neurons in the NP zones, although there were many in $P$ regions (F.-C. Liu et al., unpublished observations). As first emphasized by Isacson et al. (1987), such characteristics make it unlikely that the NP zones are striosomal but instead suggest, especially because these zones lie around marker-rich patches ( $\mathrm{P}$ zones), that the NP zones may have the phenotypy of immature matrix. If the NP regions are considered to be at the same developmental level as the $\mathrm{P}$ zones they adjoin, however, then certain of their characteristics are inconsistent with the model of these NP zones as immature matrix.

First, in normal striatal development, as soon as patches of heightened AChE staining and TH immunostaining become prominent, there is also considerable, though much weaker, $\mathrm{AChE}$ activity and TH-like immunoreactivity in the matrix around the patches (Butcher and Hodge, 1976; Graybiel, 1984a; Voorn et al., 1988). This was not the case in the NP zones, 
most of which had low AChE staining and very little TH immunostaining. In fact, by the developmental stage indicated by the presence of calbindin-positive medium-sized cells in the $\mathrm{P}$ regions (perinatal or later), TH-like immunoreactivity in the rat's striatum is quite considerable in the matrix at all anteroposterior levels, and AChE activity is appreciable in the dorsolateral matrix at most anteroposterior levels (F.-C. Liu et al., unpublished observations).

Second, as noted above, perikaryal calbindin-like immunoreactivity in medium-sized neurons is expressed perinatally, and evidence from serial section comparisons of P3 calbindin-like and TH-like striatal immunostaining (F.-C. Liu et al., unpublished observations) suggests that the calbindin antigen is already preferentially matrical (and not preferentially striosomal). The lack of calbindin-like immunostaining in medium-sized perikarya in the NP zones would thus mean (1) that the NP 7ones are at a phenotypic developmental stage earlier than that of first expression of calbindin antigen, (2) that they have the phenotypy of dorsal caudoputamen arrested at early perinatal ages before dorsal calbindin expression, or (3) that the NP zones represent exclusively dorsolateral caudoputamen of any age. The first alternative is not in accord with the age predicted by the calbindin-positive zones in the same grafts, and the second and third do not fit the low AChE activity, especially the near absence of TH-like immunoreactivity in the NP zones.

Third, in the normal developing striatum, AChE-positive neurons are not confined to the AChE-positive patches. They appear also in the matrix containing the AChE-positive patches (Graybiel et al., 1981; Nastuk and Graybiel, 1985). In the grafts, such neurons were mainly confined to $P$ zones and were comparativcly rare in NP zoncs (Graybiel et al., 1987a; F.-C. Liu et al., unpublished observations).

Fourth, in the neonatal rat, mENK-like immunoreactivity in medium-sized neural perikarya tends to be stronger in matrical neurons than in striosomal neurons and tends to follow regional gradients similar to those of medium-sized perikaryal calbindinlike immunoreactivity. The lack of mENK-like immunostaining in medium-sized neurons in NP regions adjoining $\mathrm{P}$ zones with such immunostaining is inconsistent with the NP zones as immature matrix if the $\mathrm{P}$ and NP zones are considered to be at the same developmental stage from the same part of the striatum.

In the neonatal ( $\mathrm{P} 0-\mathrm{P} 7)$ rat's striatum, there is a population of relatively large striatal neurons expressing calbindin-like immunoreactivity (F.-C. Liu et al., unpublished observations). Clearly, these could contribute to the population of large multipolar calbindin-positive neurons in the NP regions of the grafts. They are not clustered in neonates and appear to lie mainly in dorsolateral parts of the neonatal striatum where calbindin-like antigen is not yet expressed in medium-sized neurons. In fact, at $\mathrm{PO}$ and $\mathrm{P3}$, there is minimal overlap between the fields with large and with medium-sized calbindin-positive neurons. The association of NP zones having large calbindin-positive neurons with $\mathrm{P}$ zones having medium-sized calbindin-stained cells would thus once again suggest a compartmental mixture of ventrocaudal and rostrodorsal striatal counterparts if NP as well as $\mathrm{P}$ zones are striatal; that is, the $P$ zones would correspond to ventrocaudal caudoputamen, and the NP zones would correspond to rostrodorsal striatum.

It is not known whether the larger calbindin-positive cells in the neonates transiently express calbindin-like antigen or are a transient cell population. One possibility is that they could be nonstriatal cells migrating through the striatum. Some cells of this type appear in the white matter of the ventral corona radiata. At these same early postnatal ages, there are plentiful large multipolar calbindin-positive cells in the ventrolateral cortex.

In summary, most of the evidence obtained suggests that combinations of region-specific attributes of immature striatum are not faithfully replicated in the grafts when $\mathrm{P}$ and NP zones are considered together as having the same maturational status. The evidence favors $\mathbf{P}$ zones as containing considerable amounts of matrix-like tissue. The findings are not conclusive with respect to the maturity of the NP zones but are compatible with these zones as containing nonstriatal tissue or immature striatal tissue with some intermixed nonstriatal neurons. Given that TH-containing afferents do innervate the grafts, the near lack of TH-like immunoreactivity in the NP zones suggests that they would, if striatal, resemble very immature striatum.

It is important to stress that nearly all of our comparisons with immature striatum are so far limited to postnatal stages and that positive identifiers of the level of maturity for most striatal cell types are not yet available. It also is not clear that the degree of development of adjoining $\mathrm{P}$ and NP zones in the grafts is equivalent. In fact, based on the reduced density of spines on Golgi-impregnated medium-sized neurons in the grafts, McAllister et al. (1985) concluded that the grafted neurons are relatively immature. By contrast, DiFiglia et al. (1988) reported that the neuronal organization of such grafts appears mature by 5-6 weeks after transplantation. Finally, it is not certain that cells of the P and NP zones would in all aspects mimic, in the graft environment, normal patterns of expression of the markers screened.

The issuc of the maturational status of the grafts may be further complicated by cross-tissue inductive effects. For example, if the NP regions contained cortical, pallidal, or basolateral amygdaloid cells, these nonstriatal cells may have stimulated the maturation of striatal cells in the $P$ regions. The cortex, pallidum, and basolateral amygdala all project to the striatum, and the pallidum is a major target of striatal efferents. Experiments with organolypic tissue cultures of striatum suggest that striatal neurons need to be co-cultured with cortical explants in order to develop spines and mature axospinous synaptic inputs (Whetsell et al., 1979). Nonstriatal cells of the transplants, ingrowing $\mathrm{TH}$-containing or other afferents, or efferent connections made by the grafts could exert comparable inductive influences (Pritzel et al., 1986; Lanca et al., 1986; Graybiel et al., 1987a; Isacson et al., 1987; Wictorin et al., 1987, 1988; Rutherford et al., 1987; Clarke et al., 1988; Xu et al., 1988). Afferent regulation of neurotransmitter and receptor expression is well known for the striatum (see, e.g., Young et al., 1986; Eghbali et al., 1987).

\section{Factors underlying modularity in the grafts}

A major implication of these and previous experiments on fetal striatal grafts is that the modular design of these grafts may reflect a sorting out of cells of different types in what here are called the $\mathrm{P}$ and NP regions of the grafts. This would be so even if the $\mathrm{P}$ zones mainly represented host striatum and the NP zones contained most of the donor cells (see above). The protocol for preparation of the grafts yields suspensions of predominantly single cells with very few cell clumps (Brundin et al., 1985). Thus, cells of similar types appear to have reaggregated, presumably by virtue of cell-specific adhesion molecules expressed on their surfaces. The aggregation could have occurred 
during the interval between preparation of the suspensions and their injections (a matter of minutes) or in situ in the grafts. Aggregation of neurons and substantial neuronal migration between aggregates has been observed in striatal cell cultures (Surmeier et al., 1987). The compartmentalization of the grafts also may have been influenced by subsequent ingrowth of afferent fibers attracting particular subsets of the transplanted cells to themselves or repelling others. However, modularity of fetal striatal grafts has been observed also in intraocular striatal graft preparations where no graft-host connections form (Johnston et al., 1987).

Different interpretations of the modularity of fetal striatal grafts bear directly on what factors may be responsible for the architecture. If the grafts are composed of striatal tissue arrested at an immature stage of development, this would mean that the grafts can reconstitute the macroscopic morphological characteristics of normal neostriatal compartmentalization but that cues for maturation of the compartments are missing or inadequate. This would be a situation analogous to the effects of certain mutations in invertebrates (Horvitz et al., 1983).

Our own experiments do not favor reconstitution of normal striosome-matrix modularity by P-NP compartmentalization, even at an arrested stage of development, because the $\mathrm{P}$ zones seem more like matrix than like striosomes. The findings are, however, consistent with other types of compartmentalization of striatal tissues arrested at immature stages. For example, the patchiness of the grafts could reflect a segregation of tissue resembling immature dorsal striatal districts in NP zones and tissue resembling immature ventral striatal districts of the same developmental stage in $\mathrm{P}$ zones. Alternatively, the $\mathrm{P}$ and NP zones might both represent immature striatum but be at different developmental stages. If this were true, it could be argued, for example, that TH-positive fibers innervate $\mathrm{P}$ but not NP zones because the $\mathbf{P}$ zones are mature enough to trigger or to receive the ingrowth but that the NP zones are not.

Another possibility is that the modularity of the grafts might reflect a compartmentalization of striatal and nonstriatal types of tissue. According to this hypothesis, many biochemical and morphological characteristics of the normal adult rat's striatum may be duplicated in the $P$ regions of the graft tissue, even some matrix-striosome-like modularity, but the NP regions may primarily comprise nonstriatal tissue. This possibility would suggest that the formation of compartments resulted from a separation of cells of fundamentally different tissue types. It makes no specific prediction about the level of maturation of the different compartments other than to suggest that they need not be similar. Indeed, if the $\mathbf{P}$ and NP tissues are fundamentally different, they might be responsive to different maturational cues or respond differently to signals for which they share receptivity.

\section{Functional implications}

The behavioral tests on which striatal grafts have been found to induce recovery from deficits induced by striatal lesions include spontaneous locomotor activity, amphetamine- and apomorphine-induced rotation, skilled paw-reaching, and delayed alternation learning in T-mazes (Deckel et al., 1986; Isacson et al., 1986; Sanberg et al., 1986; Dunnett et al., 1988). For some of these tests, it may simply be necessary for the grafted cells to exert a diffuse regulatory influence over host targets, such as the globus pallidus, without the requirement that the grafted neurons receive normal afferent innervation from the host. However, for the grafts to influence behavior in other test sit- uations, such regulatory control from afferent systems of the host is probably essential. It would, therefore, be a necessary condition for graft-induced behavioral recovery from striatal lesions that particular populations of afferent fibers establish connections with the appropriate subpopulations of neurons within the grafts, and that these "striatal replacement neurons" in turn establish appropriate efferent connections within the host brain.

Afferent connections from host midbrain and forebrain do innervate striatal grafts (see above). There apparently is a reinstatement of normal nigrostriatal connectivity within the $\mathrm{P}$ regions of the grafts (Pritzel et al., 1986; Isacson et al., 1987; Graybiel et al., 1987a; Clarke et al., 1988). Moreover, at least some of these innervated graft neurons can be retrogradely labeled by injection of HRP into the globus pallidus (D. J. Clarke and S. B. Dunnett, unpublished observations) and can induce increases in release of GABA in the globus pallidus of the host (Sirinathsinghji et al., 1988). Accordingly, certain trans-striatal circuits do appear to run specifically through the $P$ regions of the grafts. Although the $\mathrm{P}$ regions take up a small proportion of total graft volume, the grafts are themselves extremely large so that this proportion may be sufficient to meet some functional demands. Given the results summarized here, it is interesting that the abundant efferent connectivity of fetal striatal grafts with the host's pallidum (D. J. Clarke and S. B. Dunnett, unpublished observations; Wictorin et al., 1988) but the apparent low efferent connectivity of such grafts with the substantia nigra (Pritzel et al., 1986) is similar to the pattern of output of striatal matrix in adult rats (Gerfen, 1984, 1985).

If there were considerable nonstriatal tissue in the NP regions, this might account for the lack of appreciable innervation of NP zones by TH-containing afferents (Pritzel et al., 1986; Isacson et al., 1987; Graybiel et al., 1987a). For these (or other) ingrowing fibers normally innervating striatal tissue, terminal ramifications might be inhibited while the fibers are in an NP zone, but be promoted in $\mathrm{P}$ zones. This reconstitution of normal connectivity could be crucial for behavioral recovery. On the other hand, a considerable amount of nonstriatal tissue (or developmentally arrested striatal tissue) in the graft could be functionally deleterious, not just by occupying space that striatal neurons otherwise could grow in but also by providing a framework for an aberrant pattern of connections that might compete with the appropriate reconstitution of striatal circuitry. Behavioral studies have yielded little evidence for severely abnormal functioning of the grafts, but the functional recovery so far detected has been only partial even for simple tests.

From the practical point of view, the most important aspect of our findings is that they stress the need, in future work with graft tissue, to obtain selective sets of donor neurons with methods that do not compromise the viability or developmental potential of the cells. Only then may it be possible to obtain a full repertoire of behavioral recovery.

\section{References}

Armstrong, D. M., G. Bruce, L. B. Hersh, and F. H. Gage (1987) Development of cholinergic neurons in the septal/diagonal band complex of the rat. Dev. Brain Res. 36: 249-256.

Baimbridge, K. G., J. J. Miller, and C. O. Parkes (1982) Calciumbinding protein distribution in rat brain. Brain Res. 239: 519-525.

Besson, M.-J., A. M. Graybiel, and B. Quinn (1986) Coexistence of dynorphin B-like and substance P-like immunoreactivity in striatal neurons in the cat. Soc. Neurosci. Abstr. 12:876.

Besson, M.-J., A. M. Graybiel, and M. Nastuk (1988a) SCH 23390 
ligand binding for striatal D1 dopamine receptors: Distribution follows striosomal ordering in cat, monkey and human. Neuroscience 26: 101-119.

Besson, M.-J., A. M. Graybiel, and B. Quinn (1988b) Patterns of coexistence of neuropeptides and glutamic acid decarboxylase in neurons of the feline striatum. Soc. Neurosci. $\Lambda$ bstr. 14: 156.

Bigrami, A., L. F. Eng, D. Dahl, and C. T. Uyeda (1972) Localization of the glial fibrillary acidic protein in astrocytes by immunofluorescence. Brain Res. 43: 429-435.

Björklund, A., O. Lindvall, O. Isacson, P. Brundin, K. Wictorin, R. Strecker, D. J. Clarke, and S. B. Dunnett (1987) Mechanisms of action of intracerebral neural implants: Studies on nigral and striatal grafts to the lesioned striatum. Trends Neurosci. 10: 509-516.

Brundin, P., O. Isacson, and A. Björklund (1985) Monitoring of cell viability in suspensions of embryonic CNS tissue and its use as a criterion for intracerebral graft survival. Brain Res. 331: 251-259.

Butcher, L. L. (1983) Acetylcholinesterase histochemistry. In Handbook of Chemical Neuroanatomy, Vol. I: Method in Chemical Neuroanatomy, A. Björklund and T. Hökfelt, eds., pp. 1-49, Elsevier, $\Lambda$ msterdam.

Butcher, L. L., and G. K. Hodge (1976) Postnatal development of acetylcholinesterase in the caudate putamen and substantia nigra of rats. Brain Res. 106: 223-240.

Clarke, D. J., S. B. Dunnett, O. Isacson, D. J. S. Sirinathsinghji, and A. Björklund (1988) Striatal grafts in rats with unilateral neostriatal lesions. I. Ultrastructural evidence of afferent synaptic inputs from the host nigrostriatal pathway. Neuroscience 24: 791-801.

Coyle, J. T., and R. Schwarcz (1976) Lesions of striatal neurons with kainic acid provide a model for Huntington's chorea. Nature 263: 244-246.

Deckel, A. W., T. H. Moran, J. T. Coyle, P. R. Sanberg, and R. G. Robinson (1986) Anatomical predictors of behavioral recovery following fetal striatal transplants. Brain Res. 365: 249-258.

Deckel, A. W., and R. G. Robinson (1987) Receptor characteristics and behavioral consequences of kainic acid lesions and fetal transplants of the striatum. Ann. NY Acad. Sci. 495: 556-580.

DiFiglia, M., L. Schiff, and A. W. Deckel (1988) Neuronal organization of fetal striatal grafts in kainate- and sham-lesioned rat caudate nucleus: Light- and electron-microscopic observations. J. Neurosci. 8: $1112-1130$.

Dunnett, S. B., O. Isacson, D. J. S. Sirinathsinghji, D. J. Clarke, and A. Björklund (1988) Striatal grafts in rats with unilateral neostriatal lesions. III. Recovery from dopamine-dependent motor asymmetry and deficits in skilled paw reaching. Neuroscience 24: 813-820.

Eghbali, M., C. Santoro, W. Paredes, E. L. Gardner, and R. S. Zukin (1987) Visualization of multiple opioid-receptor types in rat striatum after specific mesencephalic lesions. Proc. Natl. Acad. Sci. USA 84: 6582-6586.

Emson, P. C., G. Paxinos, G. Le Gal La Salle, Y. Ben-Ari, and A. Silver (1979) Choline acetyltransferase and acetylcholinesterase containing projections from the basal forebrain to the amygdaloid complex of the rat. Brain Res. 165: 271-282.

Eriksdotter-Nillson, M., H. Björklund, and L. Olson (1986) Laminin immunohistochemistry: A simple method to visualize and quantitate vascular structures in the mammalian brain. J. Neurosci. Methods $17: 275-286$.

Fallon, J. H., and S. E. Loughlin (1987) Monoamine innervation of cerebral cortex and a theory of the role of monoamines in cerebral cortex and basal ganglia. In Cerebral Cortex, Vol. 6, E. G. Jones and A. Peters, eds., pp. 41-127, Plenum, New York.

Fallon, J. H., K. B. Seroogy, S. E. Loughlin, R. S. Morrison, R. A. Bradshaw, D. J. Knauer, and D. D. Cunningham (1984) Epidermal growth factor immunoreactive material in the central nervous system: Location and development. Science 224: 1107-1109.

Ferrante, R. J., and N. W. Kowall (1987) TH-like immunoreactivity is distributed in the matrix component of normal human and Huntington's disease striatum. Brain Res. 416: 141-146.

Geneser-Jensen, F. A., and J. W. Blackstad (1971) Distribution of acetylcholinesterase in the hippocampal region of the guinea pig. $\mathrm{Z}$. Zellforsch. Mikrosk. Anat. 114: 460-481.

Gerfen, C. R. (1984) The neostriatal mosaic: Compartmentalization of corticostriatal input and striatonigral output systems. Nature 311 : $461-464$.

Gerfen, C. R. (1985) The neostriatal mosaic. I. Compartmental or- ganization of projections from the striatum to the substantia nigra in the rat. J. Comp. Neurol. 236: 454-476.

Gerfen, C. R., K. G. Baimbridge, and J. J. Miller (1985) The neostriatal mosaic: Compartmental distribution of calcium binding protein and parvalbumin in the basal ganglia of the rat and monkey. Proc. Natl. $\Lambda$ cad. Sci. US $\Lambda$ 82: 8780-8784.

Gerfen, C. R., M. Herkenham, and J. Thibault (1987a) The neostriatal mosaic: II. Patch- and matrix-directed mesostriatal dopaminergic and non-dopaminergic systems. J. Neurosci. 7: 3915-3934.

Gerfen, C. R., K. G. Baimbridge, and J. Thibault (1987b) The neostriatal mosaic: III. Biochemical and developmental dissociation of patch-matrix mesostriatal systems. J. Neurosci. 7: 3935-3944.

Graybiel, A. M. (1984a) Correspondence between the dopamine islands and striosomes of the mammalian striatum. Neuroscience 13: 1157-1187.

Graybiel, A. M. (1984b) Neurochemically specified subsystems in the basal ganglia. In Functions of the Basal Ganglia (Ciba Foundation Symposium 107), pp. 114-149, Pitman, London.

Graybiel, A. M. (1986) Neuropeptides in the basal ganglia. In Neuropeptides in Neurologic and Psychiatric Disease, J. B. Martin and J. D. Barchas, eds., pp. 135-161, Raven, New York.

Graybiel, A. M. (1989) Dopaminergic and cholinergic systems in the striatum. In Neural Mechanism in Disorder of Movement, A. Crossman and M. A. Sambrook, eds., pp. 3-15, Linney, London.

Graybiel, A. M., and M. F. Chesselet (1984a) Compartmental distribution of striatal cell bodies expressing met-enkephalin-like immunoreactivity. Proc. Natl. Acad. Sci. USA 81: 7980-7984.

Graybiel, A. M., and M. F. Chesselet (1984b) Distribution of cell bodies expressing substance $P$, enkephalin and dynorphin $B$ in kitten and cat striatum. Anat. Rec. 208: 64A.

Graybiel, A. M., and C. W. Ragsdale (1978) Histochemically distinct compartments in the striatum of human, monkey, and cat demonstrated by acetylthiocholinesterase staining. Proc. Natl. Acad. Sci. USA 75: 5723-5726.

Graybiel, A. M., and C. W. Ragsdale (1983) Biochemical anatomy of the striatum. In Chemical Neuroanatomy, P. C. Emson, ed., pp. 427504, Raven, New York.

Graybiel, A. M., V. M. Pickel, T. H. Joh, D. J. Reis, and C. W. Ragsdale (1981) Direct demonstrations of a correspondence between the dopamine islands and acetylcholinesterase patches in the developing striatum. Proc. Natl. Acad. Sci. USA 78: 5871-5875.

Graybiel, A. M., S. B. Dunnett, R. W. Baughman, and F.-C. Liu (1987a) Cholinergic neurons and neuropil and tyrosine hydroxylase-positive fibers cluster together in circumscribed patches in intrastriatal grafts derived from embryonic striatal donor tissue. Neurosci. Suppl. 22: S265.

Graybiel, A. M., E. C. Hirsch, and Y. A. Agid (1987b) Differences in tyrosine hydroxylase-like immunoreactivity characterize the mesostriatal innervation of striosomes and extrastriosomal matrix at maturity. Proc. Natl. Acad. Sci. USA 84: 303-307.

Herkenham, M., and C. B. Pert (1981) Mosaic distribution of opiate receptors, parafascicular projections and acetylcholinesterase in rat striatum. Nature 291: 415-418.

Herkenham, M., and C. B. Pert (1982) Light microscopic localization of brain opiate receptors: A general autoradiographic method which preserves tissue quality. J. Neurosci. 2: 1129-1149.

Hökfelt, T., R. Mårtensson, A. Björklund, S. Kleinau, and M. Goldstein (1984) Distributional maps of tyrosine-hydroxylase-immunoreactive neurons in the rat brain. In Handbook of Chemical Neuroanatomy, Vol. II: Classic Transmitters in the CNS, part I, A. Björklund and T. Hökfelt, eds., pp. 277-379, Elsevier, Amsterdam.

Horvitz, H. R., P. W. Sternberg, I. S. Greenwald, W. Fixsen, and H. M. Ellis (1983) Mutations that affect neural cell lineages and cell fates during the development of the nematode Caenorhabditis elegans. In Molecular Neurobiology, Vol. XLVIII: Cold Spring IIarbor Symposia on Quantitative Biology, J. D. Watson and R. McKay, eds., pp. 453-463, Cold Spring Harbor, New York.

Isacson, O. (1987) Neural Grafting in an Animal Model of Huntington's Disease, Doctoral Dissertation, Lund, Sweden.

Isacson, O., P. Brundin, P. A. T. Kelly, F. H. Gage, and A. Björklund (1984) Functional neuronal replacement by grafted striatal neurons in the ibotenic acid-lesioned rat striatum. Nature 311: 458-460.

Isacson, O., P. Brundin, F. H. Gage, and A. Björklund (1985) Neural grafting in a rat model of Huntington's disease: Progressive neuro- 
chemical changes after neostriatal ibotenate lesions and striatal tissue grafting. Neuroscience 16: 799-817.

Isacson, O., S. B. Dunnett, and A. Björklund (1986) Graft-induced behavioral recovery in an animal model of Huntington's disease. Proc. Natl. Acad. Sci. USA 83: 2728-2732.

Isacson, O., D. Dawbarn, P. Brundin, F. H. Gage, P. C. Emson, and A. Björklund (1987) Neural grafting in a rat model of Huntington's disease: Striosomal-like organization of striatal grafts as revealed by immunohistochemistry and receptor autoradiography. Neuroscience 22: 481-497.

Johnston, J., S. R. Boyd, and D. van der Kooy (1987) Compartmentalization of the embryonic striatum after intraocular transplantation. Dev. Brain Res. 33: 310-314.

Kent, J. L., C. B. Pert, and M. Herkenham (1982) Ontogeny of opiate receptors in rat forebrain: Visualization by in vitro autoradiography. Dev. Brain Res. 2: 487-504.

Köhler, C., and R. Schwarcz (1983) Comparison of ibotenic and kainate neurotoxicity in the rat brain: A histological study. Neuroscience 8: 819-835.

Lanca, A. J., S. Boyd, B. E. Kolb, and D. van der Kooy (1986) The development of a patchy organization of the rat striatum. Dev. Brain Res. 27: 1-10.

McAllister, J. P. (1987) Tritiated thymidine identification of embryonic neostriatal transplants. Ann. NY Acad. Sci. 495: 745-748.

McAllister, J. P., P. D. Walker, M. C. Zemanick, A. B. Weber, L. I. Kaplan, and M. A. Reynolds (1985) Morphology of embryonic neostriatal cell suspensions transplanted into adult neostriata. Dev. Brain Res. 23: 282-286.

McGeer, P. L., H. Kimura, and E. G. McGeer (1984) Transplantation of newborn brain tissue into adult kainic-acid-lesioned neostriatum. In Neural Transplants, Development and Function, J. R. Sladek and D. M. Gash, eds., pp. 361-371, Plenum, New York.

Moon Edley, S., and M. Herkenham (1984) Comparative development of striatal opiate receptors and dopamine revealed by autoradiography and histofluorescence. Brain Res. 305: 27-42.

Nastuk, M. A., and A. M. Graybiel (1985) Patterns of muscarinic cholinergic binding in the striatum and their relation to dopamine islands and striosomes. J. Comp. Neurol. 237: 176-194.

Pritzel, M., O. Isacson, P. Brundin, L. Wiklund, and A. Björklund (1986) Afferent and efferent connections of striatal grafts implanted into the ibotenic acid lesioned neostriatum in adult rats. Exp. Brain Res. 65: 112-126.

Roberts, R. C., and M. DiFiglia (1988) Localization of immunoreactive GABA and enkephalin and NADPH-diaphorase-positive neurons in fetal striatal grafts in the quinolinic-acid-lesioned rat neostriatum. J. Comp. Neurol. 274: 406-421.

Rutherford, A., M. Garcia-Munoz, S. B. Dunnett, and G. W. Arbuthnott (1987) Electrophysiological demonstration of host cortical inputs to striatal grafts. Neurosci. Lett. 83: 275-281.

Sanberg, P. R., M.A. Henault, and A. W. Deckel (1986) Locomotor hyperactivity: Effects of multiple striatal transplants in an animal model of Huntington's disease. Pharmacol. Biochem. Behav. 25: 297300 .

Sanberg, P. R., M. A. Henault, S. H. Hagenmeyer-Houser, M. Giordano, and K. H. Russell (1987) Multiple transplants of fetal striatal tissue in the kainic acid model of Huntington's disease: Behavioral recovery may not be related to acetylcholinesterase. Ann. NY Acad. Sci. 495: $781-785$.

Shiosaka, S., K. Takatsuki, M. Sakanaka, S. Inagaki, H. Takagi, E. Senba, Y. Kawai, H. Iida, H. Minagawa, Y. Hara, T. Matsuzaki, and M. Tohyama (1982) Ontogeny of somatostatin-containing neuron system of the rat: Immunohistochemical analysis. II. Forebrain and diencephalon. J. Comp. Neurol. 204: 211-224.

Sirinathsinghji, D. J. S., S. B. Dunnett, O. Isacson, D. J. Clarke, K. Kendrick, and A. Björklund (1988) Striatal grafts in rats with unilateral neostriatal lesions. II. In vivo monitoring of GABA release in globus pallidus and substantia nigra. Neuroscicncc 24: 803-811.

Specht, L., V. M. Pickel, T. H. Joh, and D. J. Reis (1981a) Lightmicroscopic immunocytochemical localization of tyrosine hydroxylase in prenatal rat brain. II. Early ontogeny. J. Comp. Neurol. 199. 233-253.

Specht, L., V. M. Pickel, T. H. Joh, and D. J. Reis (1981b) Lightmicroscopic immunocytochemical localization of tyrosine hydroxylase in prenatal rat brain. II. Late ontogeny. J. Comp. Neurol. 199: 255-276.

Surmeier, D. J., P. Akins, and S. T. Kitai (1987) Neuronal migration in primary monolayer cultures of rat neostriatum. Soc. Neurosci. Abstr. 13: 1575.

van der Kooy, D. (1984) Developmental relationships between opiate receptors and dopamine in the formation of caudate-putamen patches. Dev. Brain Res. 14: 300-303.

van der Kooy, D., and G. Fishell (1987) Neuronal birthdate underlies the development of striatal compartments. Brain Res. 401: 155-161.

Voorn, P., A. Kalsbeek, B. Jorritsma-Byham, and H. J. Groenewegen (1988) The pre- and postnatal development of the dopaminergic cell groups in the ventral mesencephalon and the dopaminergic innervation of the striatum of the rat. Neuroscience 25: 857-887.

Walker, P. D., G. I. Chovanes, and J. P. McAllister (1987) Identification of acetylcholinesterase-reactive neurons and neuropil in neostriatal transplants. J. Comp. Neurol. 259: 1-12.

Whetsell, W. O., M. S. Ecob-Johnston, and W. J. Nicklas (1979) Studies of kainate-induced caudate lesions in organotypic tissue culture. Adv. Neurol. 23: 645-654.

Wictorin, K., O. Isacson, W. Fischer, F. Nothias, M. Peschanski, and A. Björklund (1988) Conncctivity of striatal grafts implanted into the ibotenic acid-lesioned striatum. I. Subcortical afferents. Neuroscience 27: 547-562.

Wictorin, K., O. Isacson, R. Simerly, L. W. Swanson, C. Quimet, and A. Björklund (1988) Fetal striatal grafts in the ibotenate lesioned striatum reinnervate the globus pallidus and receive specific inputs from the host. Soc. Neurosci. Abstr. 14: 887.

Xu, Z. C., C. J. Wilson, and P. C. Emson (1988) Cortical inputs in the rat striato-striatal grafts: Electron microscopic analysis with the PHA-L method. Soc. Neurosci. Abstr. 14: 74.

Young, W. S. III, T. I. Bonner, and M. R. Brann (1986) Mesencephalic dopamine neurons regulate the expression of neuropeptide mRNA in the rat forebrain. Proc. Natl. Acad. Sci. USA 83: 9827-9831. 